\title{
A Simple Method for High-Lift Propeller Conceptual Design
}

\author{
5 January 2016
}

Michael Patterson, Nick Borer, NASA Langley Research Center and Brian German

Georgia Institute of Technology 


\section{Presentation Outline}

- Introduction

- Motivation

- High-Lift Propeller Design Method \& Examples

- Conclusions \& Future Work

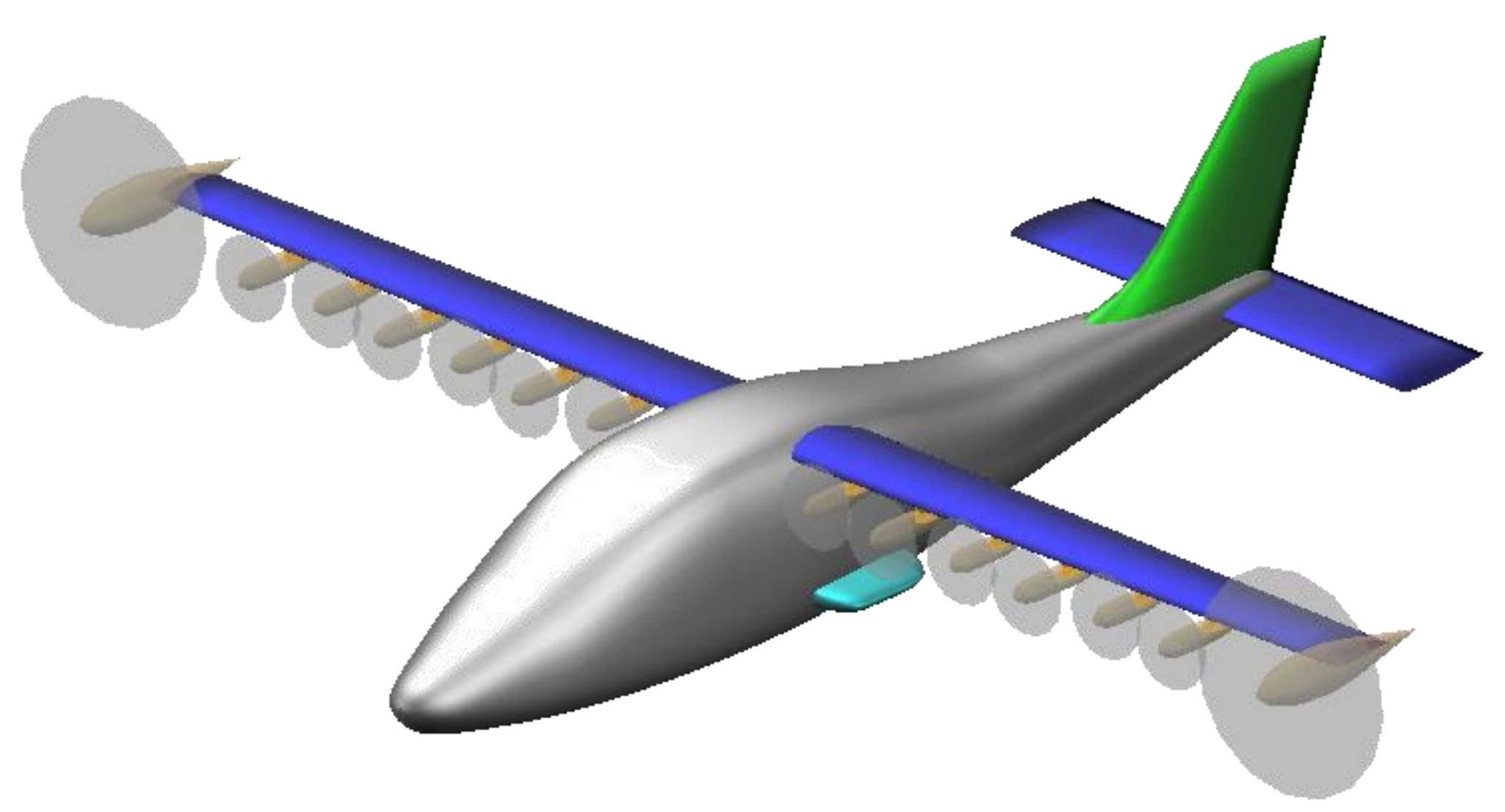

NASA's Scalable Convergent Electric Propulsion Technology and Operations Research (SCEPTOR) distributed electric propulsion concept 
(145)

Introduction 


\section{Electric motors enable propellers to be installed in}

non-traditional, beneficial manners

- Electric motors have distinctly different characteristics than conventional engines

- Lower weight and volume

- Reduced vibration

- Nearly "scale-invariant"

- Wing tip props can reduce induced drag / increase propulsive efficiency

- "High-lift props" placed upstream of a wing can increase lift
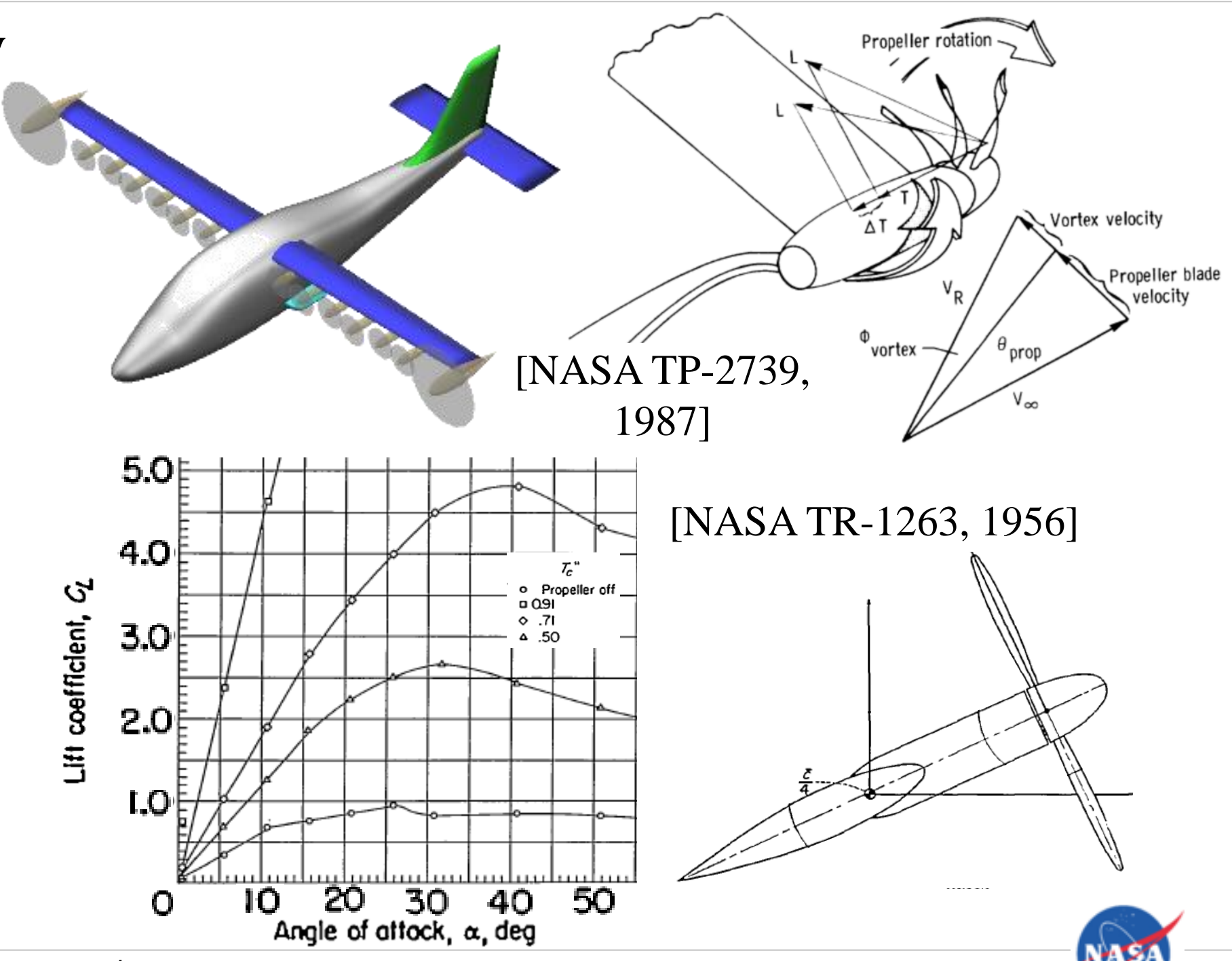

[NASA TR-1263, 1956]

- Others...

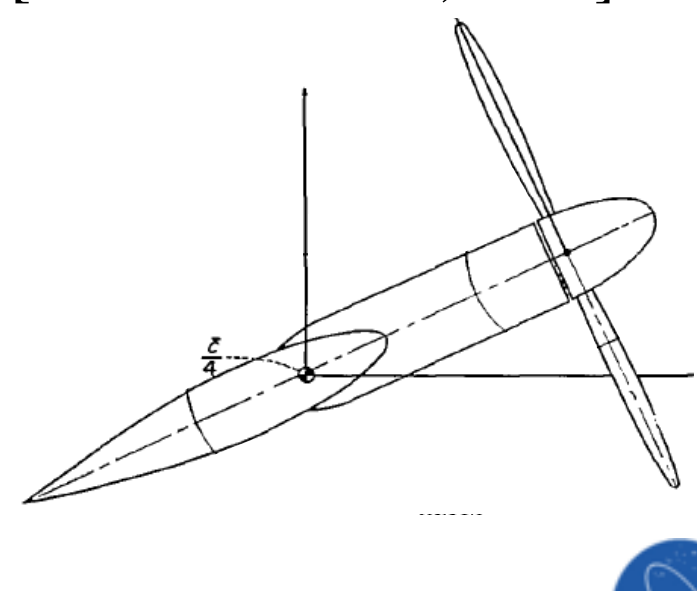




\section{Effect of prop slipstreams on downstream wings is complex, but can be approximated with a simple model}

- Propellers induce axial and tangential ("swirl") velocities

- High-lift props alter the zerolift angle of attack and lift curve slope of downstream wing sections

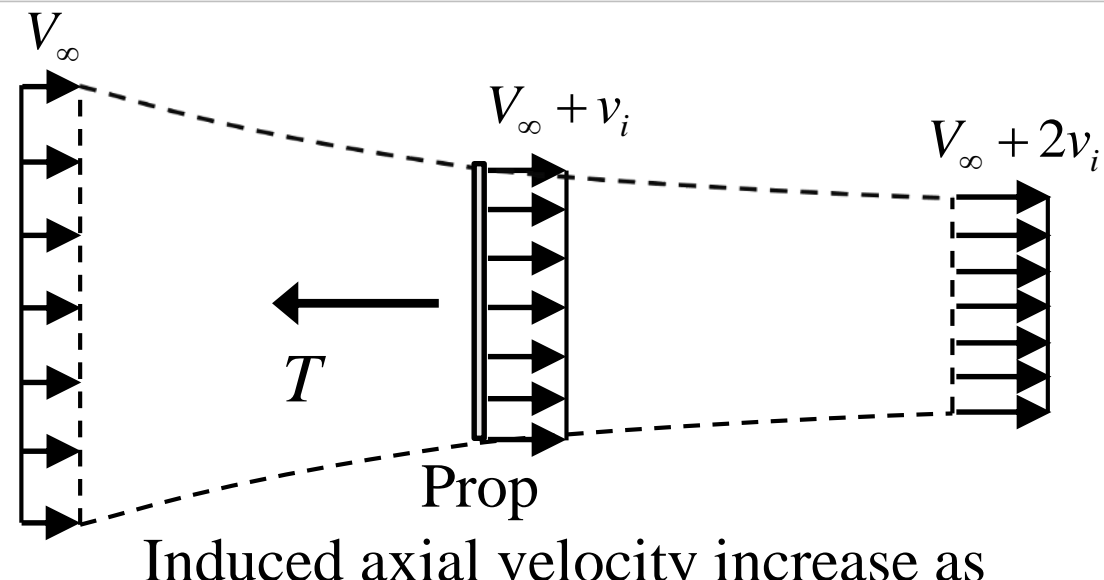

Induced axial velocity increase as predicted by momentum theory

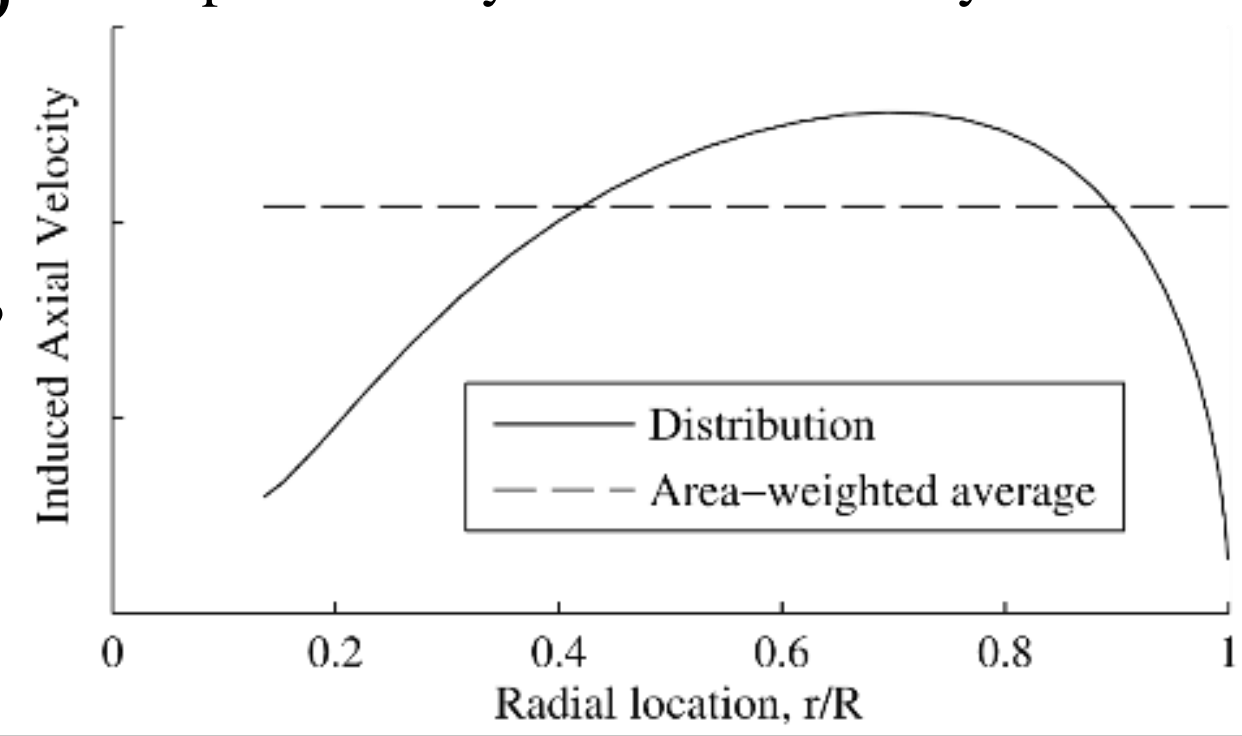

Notional propeller swirl velocity profile prop disk

- To first-order, prop impacts on lift can be assessed via a single, average induced axial velocity

$\rightarrow$ Small wing impacts on prop

$\rightarrow$ Swirl affects on either side of disk "cancel out"

Typical induced axial velocity profile 


\section{Motivation}

Should high-lift propellers be designed in the same manner as conventional propellers? 


\section{Because the goal of high-lift props differs from conventional props, they should be designed differently}

- Goal of conventional props is to produce thrust, but goal of high-lift props is to augment lift

- Thrust may actually be bad for high-lift props!

- Props primarily affect lift via induced velocity

- Chow et al. indicate that the axial velocity profile affects the lift generated

- Placed Joukowski velocity profiles upstream of airfoil and studied lift generated

- Varied airfoil height relative to profile

- Define "non-uniformity parameter": $\mathrm{a} / \mathrm{d}^{2}$

- Define "adjusted lift coefficient": $\bar{C}_{L}=\frac{C_{L}}{(1+a)^{2}}$

$$
V(z)=V_{\infty}\left(1+a e^{-z^{2} / d^{2}}\right)
$$

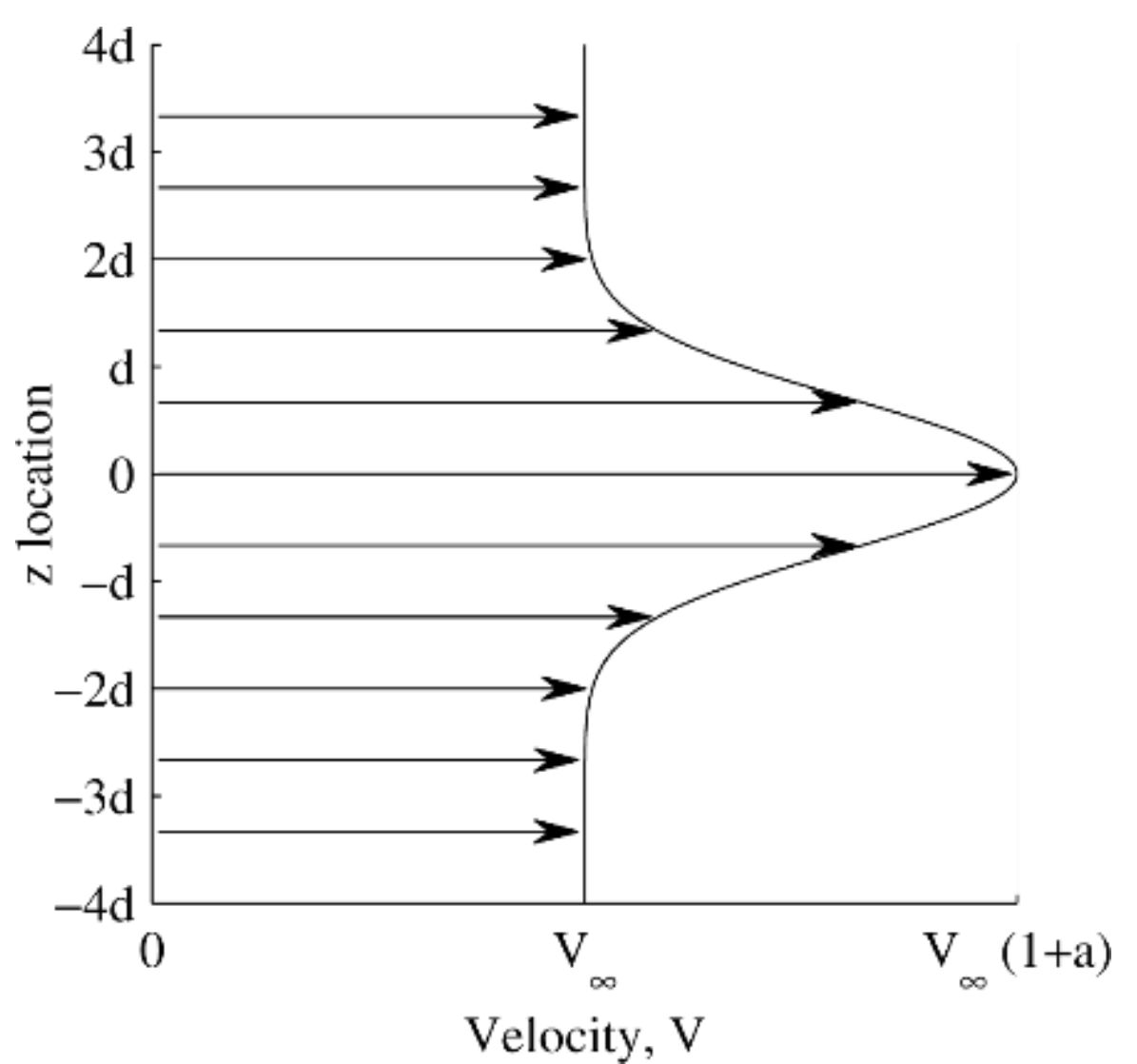

[Chow 1970, DOI 10.2514/3.44208] 


\section{Maximum lift is generated when the axial velocity profile is as closely uniform as possible}

- Chow et al. empirically determined a relationship between the adjusted lift coefficient and the non-uniformity parameter

Takeaways:
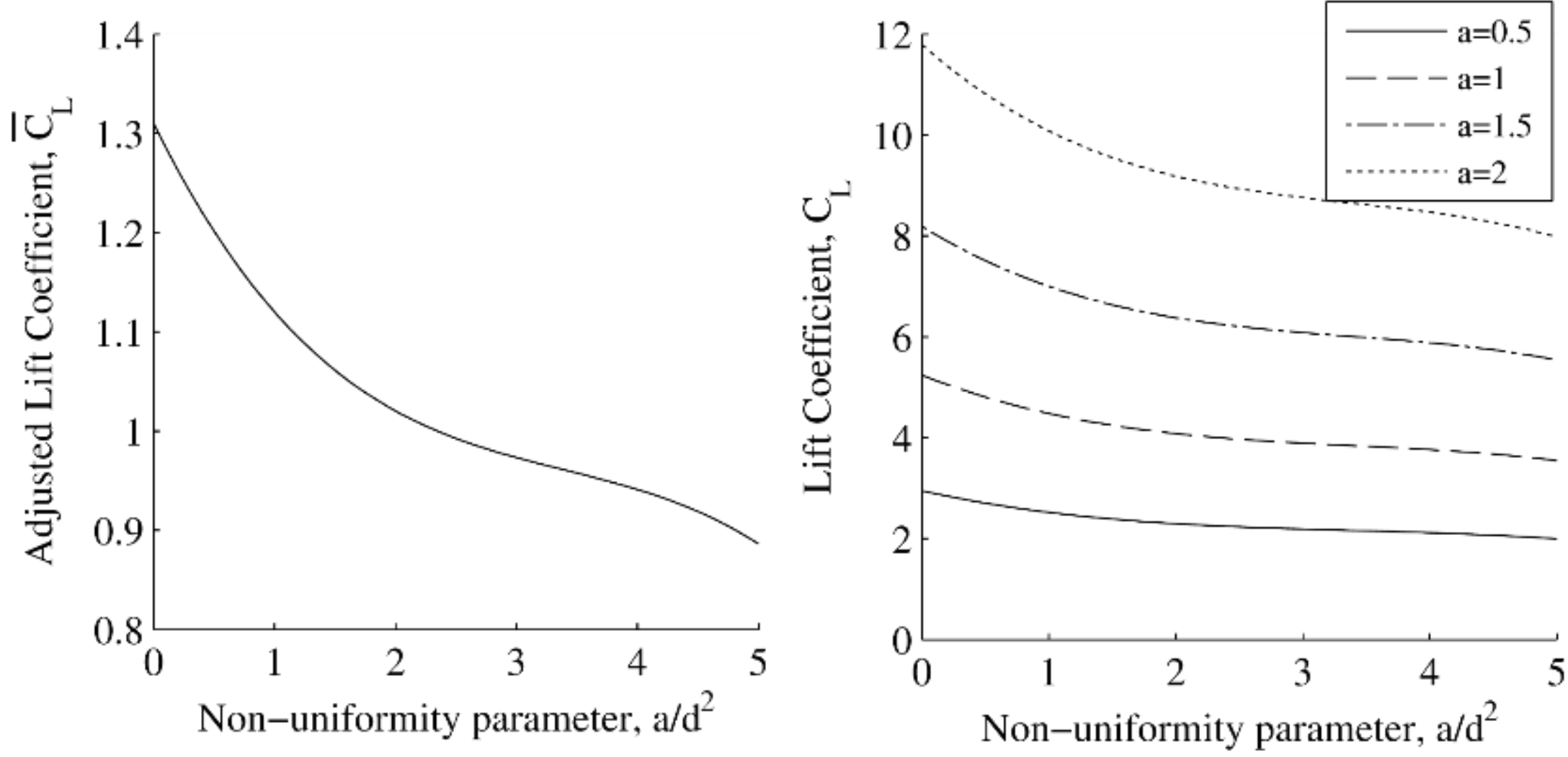

1. Lift decreases as non-uniformity increases regardless of max velocity

2. More lift produced as maximum velocity increases

3. Impact of non-uniformity increases as maximum velocity increases 


\section{Maximum lift is generated when the axial velocity profile is as closely uniform as possible}

- Chow et al. empirically $\operatorname{det} \epsilon$

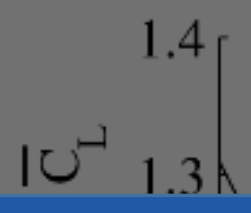

12

$\mathrm{a}=0.5$

rela betr

We hypothesize that propellers with near-uniform adji coe non high-lift propellers. par: axial velocity profiles will make the most effective

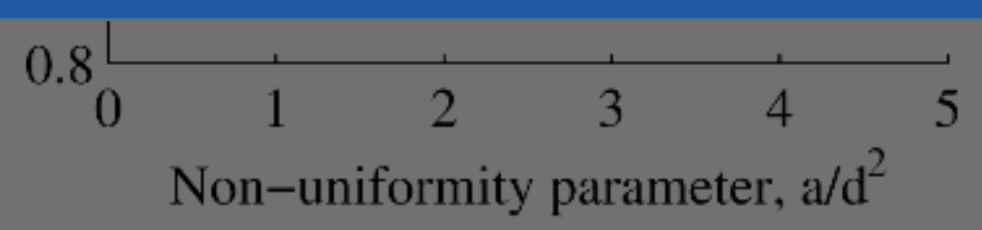

Takeaways:

1. Lift decreases as non-uniformity increases regardless of max velocity

2. More lift produced as maximum velocity increases

3. Impact of non-uniformity increases as maximum velocity increases 


\section{High-Lift Propeller Design Method \& Examples}




\section{The design method is based on BEMT and seeks to maintain a near-uniform axial velocity distribution}

- Method is built on blade element momentum theory (BEMT)

- Analyze prop as sum of many "blade elements" as 2-D airfoils

- Local velocity at airfoil sections, W, split into axial and tangential components, which are defined by the freestream, prop rotation, and prop-induced velocities

- Induced velocities presented as axial and tangential induction factors ( $\mathrm{a}$ and $\mathrm{a}$ )

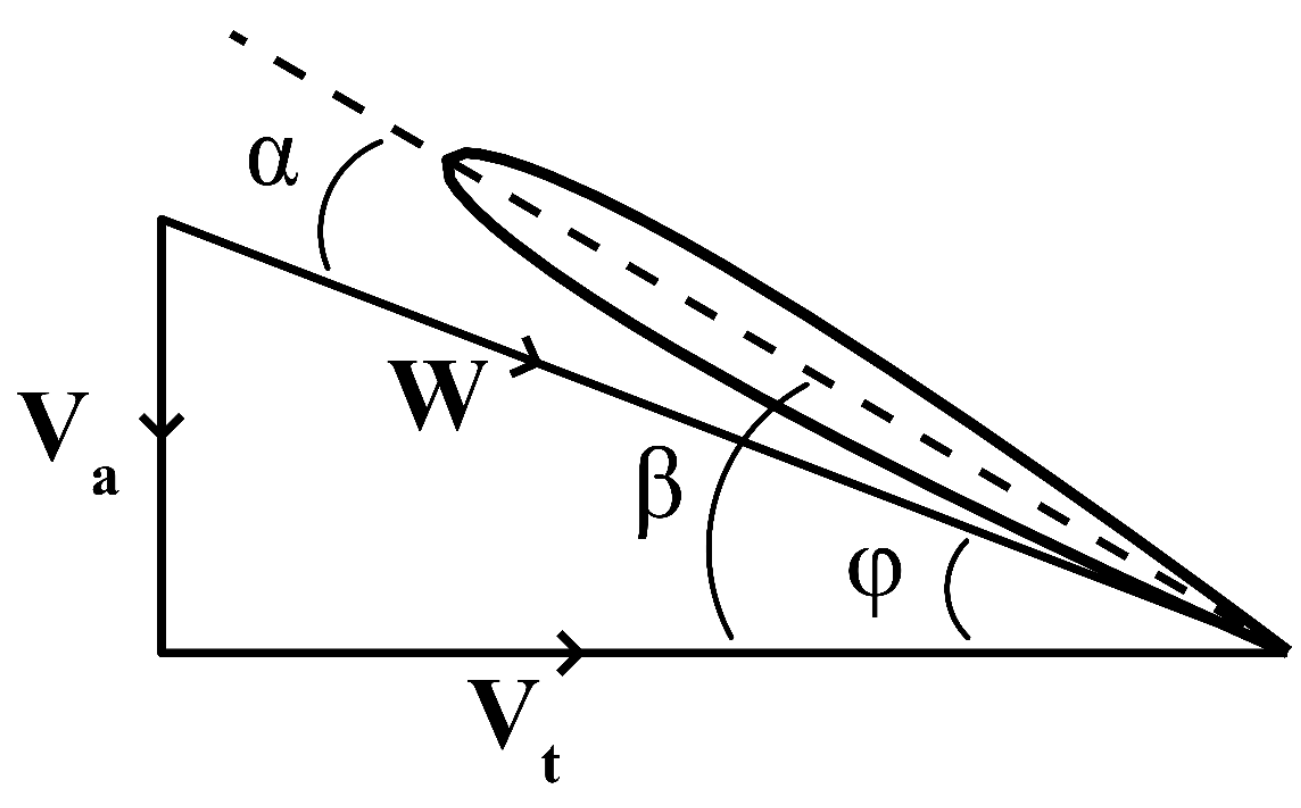

$$
\boldsymbol{V}_{\boldsymbol{a}}=V_{\infty}(1+a)
$$

- Blades are designed to a specified induced axial velocity distribution

$$
\boldsymbol{V}_{\boldsymbol{t}}=\Omega r\left(1-a^{\prime}\right)
$$




\section{The design method consists of four steps, where the first is the most important and novel}

- Assumptions:

- Designer desires constant induced axial velocity distribution

- The diameter, number of blades, rotational speed, and airfoil(s) are known

- The angular velocity added to the slipstream is small compared to the angular velocity of the propeller

- Steps in method:

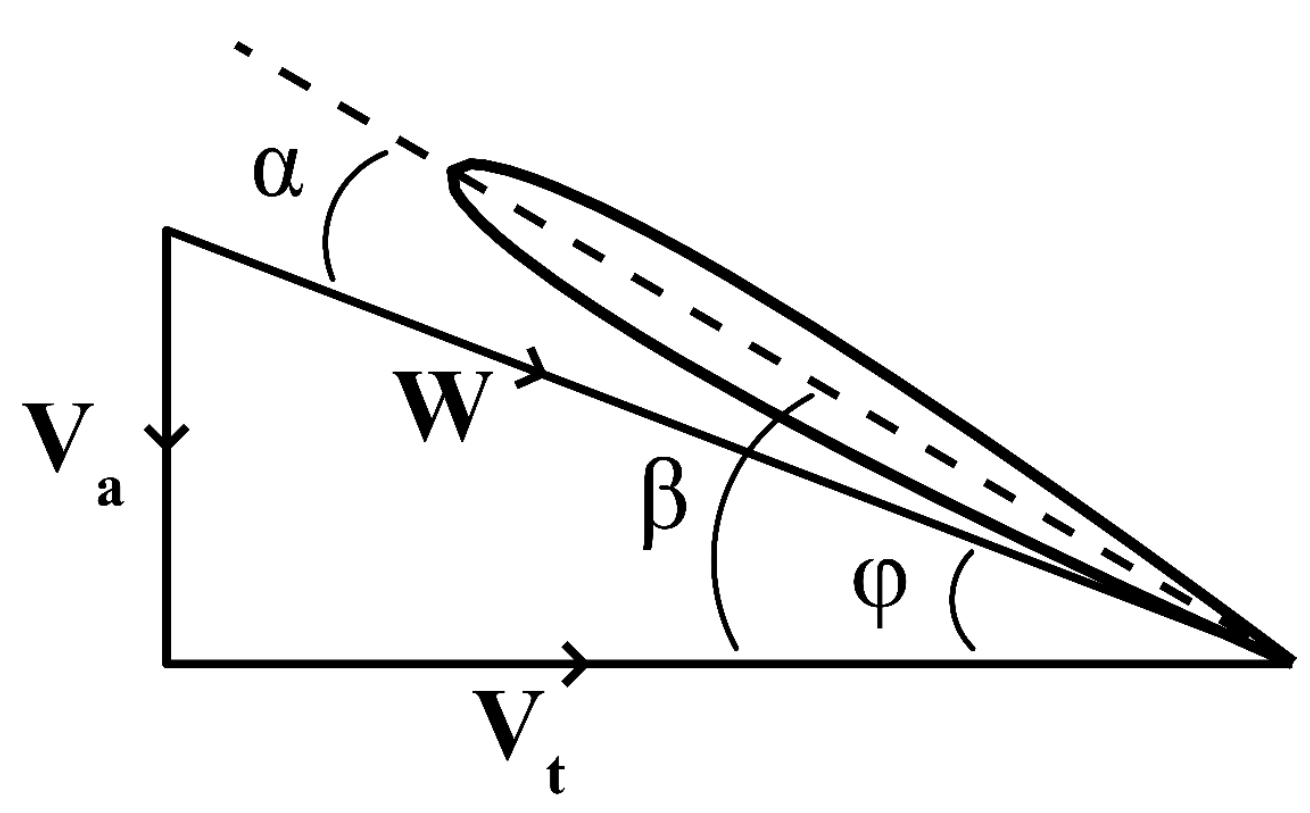

1. Set axial induction factor distribution

2. Determine blade pitch angle distribution

3. Determine blade chord length distribution

4. Verify performance and iterate (if required)

$$
\begin{aligned}
& \boldsymbol{V}_{\boldsymbol{a}}=V_{\infty}(1+a) \\
& \boldsymbol{V}_{\boldsymbol{t}}=\Omega r\left(1-a^{\prime}\right)
\end{aligned}
$$




\section{Steps 1-3: Setting the axial induction factor distribution determines the blade chord/pitch distributions}

- Begin by specifying a constant axial velocity distribution based on desired average induced velocity

- If assumptions are valid, then axial and tangential induction factors are related

- Relationship implies maximum value for $\mathrm{a}^{\prime}$ as 0.5

- If desired value of a leads to a' $>0.5$, limit

$$
a=\frac{v_{i}}{V_{\infty}}
$$
a' to 0.5

- If limiting a', find new implied value of a

$$
V_{\infty}^{2}(1+a) a=\Omega^{2} r^{2}\left(1-a^{\prime}\right) a^{\prime}
$$

$$
\begin{gathered}
a^{\prime}=\frac{1-\sqrt{1-\frac{4 V_{\infty}^{2}(1+a) a}{\Omega^{2} r^{2}}}}{2} \\
a=\frac{-1+\sqrt{1+\frac{4 \Omega^{2} r^{2}\left(1-a^{\prime}\right) a^{\prime}}{V_{\infty}^{2}}}}{2}
\end{gathered}
$$


Step 4: Verify prop performance and iterate (if required) until desired average induced axial velocity is achieved

- Average induced axial velocity from method will likely not match desired value (due to assumptions, hub/tip losses, limiting a', etc.)

- We utilize XROTOR in vortex mode to verify average axial velocity

- XROTOR is open-source prop design/analysis tool from Mark Drela's research group at MIT

- If average induced axial velocity is too low (high), increase (decrease) induced axial velocity specified in Step 1 and repeat

- In practice, found that approximately 2-3 iterations are required for convergence 


\section{Example: notional high-lift propellers for NASA's SCEPTOR flight demonstrator}

- NASA's Scalable Convergent Electric Propulsion Technology and Operations Research (SCEPTOR) project

- Developing flight demonstrator to show efficiency gains possible from distributed electric propulsion

- Retrofitting Tecnam P2006T aircraft with new, smaller wing and high-lift props

- Configuration consists of 12, 5-bladed high-lift propellers with 22.7 inch diameter

- Conceptual design studies indicate $23.2 \mathrm{ft} / \mathrm{sec}$ average induced axial velocity required at 55 knots

- For design, assume constant airfoil (MH 114), design $\mathrm{c}_{1}$ of 1.1 , rotational speed of $450 \mathrm{ft} / \mathrm{sec}, \&$ hub diameter of 5.7 inch

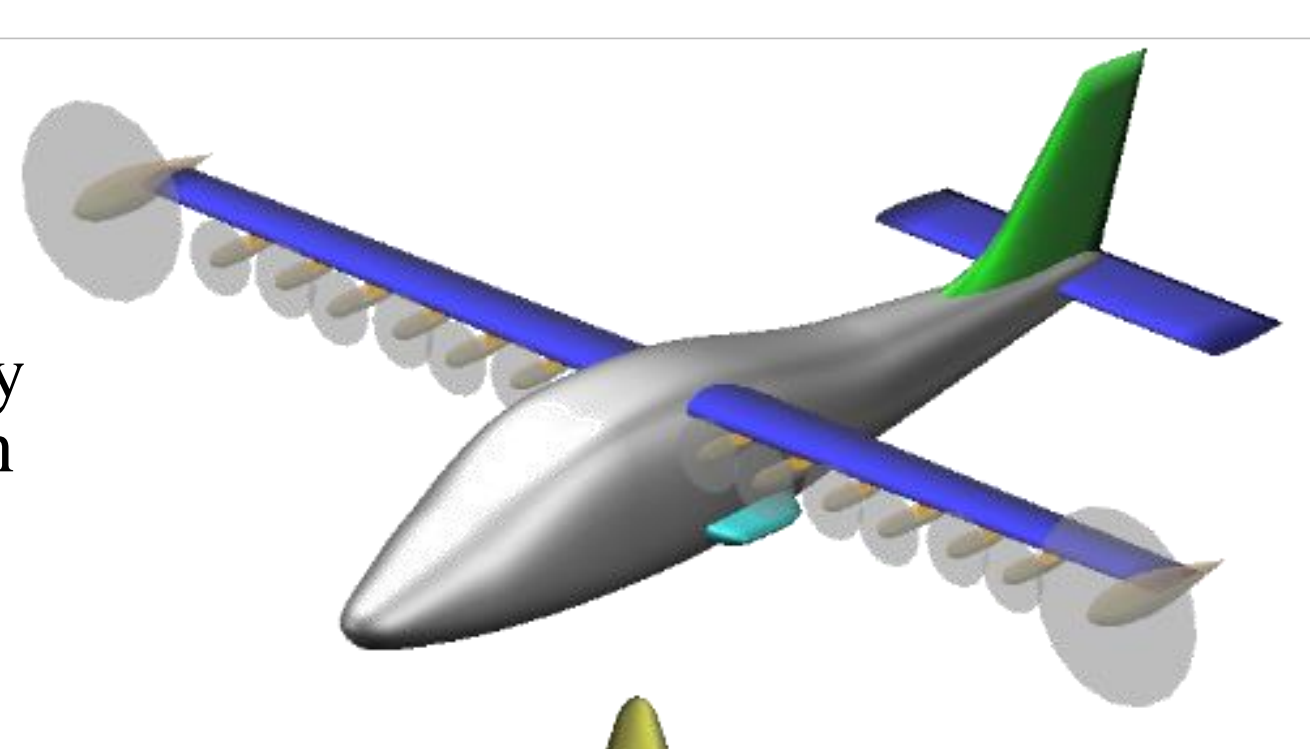




\section{A conventional, minimum induced loss (MIL) prop was designed via XROTOR for the SCEPTOR aircraft}



\section{The 1st iteration through the method produces insufficient induced axial velocity}

- Average induced velocity of $20.1 \mathrm{ft} / \mathrm{sec}$ (desired $23.2 \mathrm{ft} / \mathrm{sec}$ )
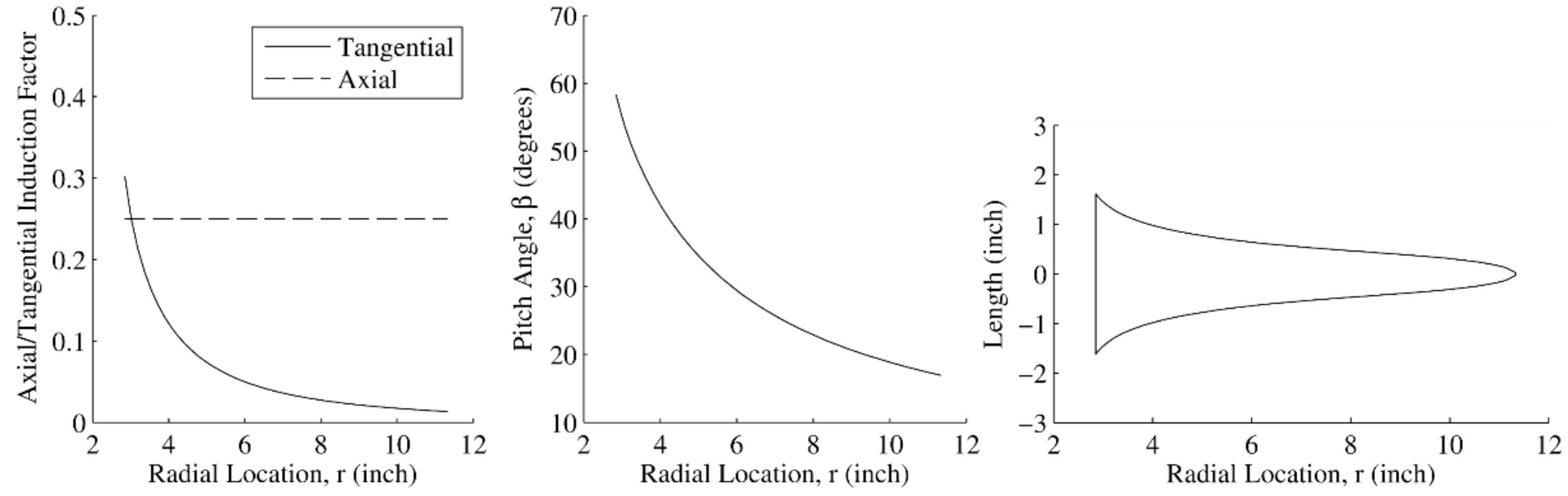


\section{The 2nd iteration through the method produces the desired induced axial velocity}
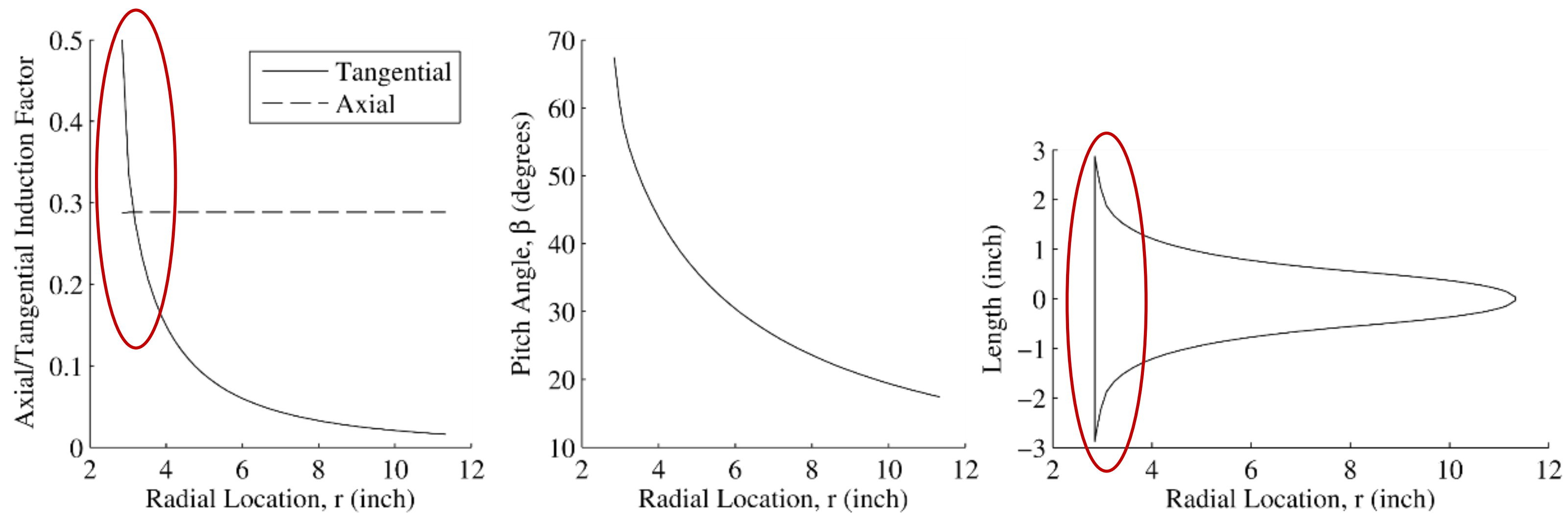

- Large chord length increases associated with large increases in the tangential induction factor 


\section{Step 1, Modification Option 2: reduce chord/twist change near root by limiting increase in a'}

- Goal: reduce large chord length and pitch angle changes near the root

- Large increases in tangential induction factor imply violation of assumption that the angular velocity added to the slipstream is small

- Limit slope of tangential induction factor vs $\mathrm{r} / \mathrm{R}$ curve

- In practice found $\mathrm{da} / \mathrm{d}(\mathrm{r} / \mathrm{R}) \approx 1.25$ provides the desired effect

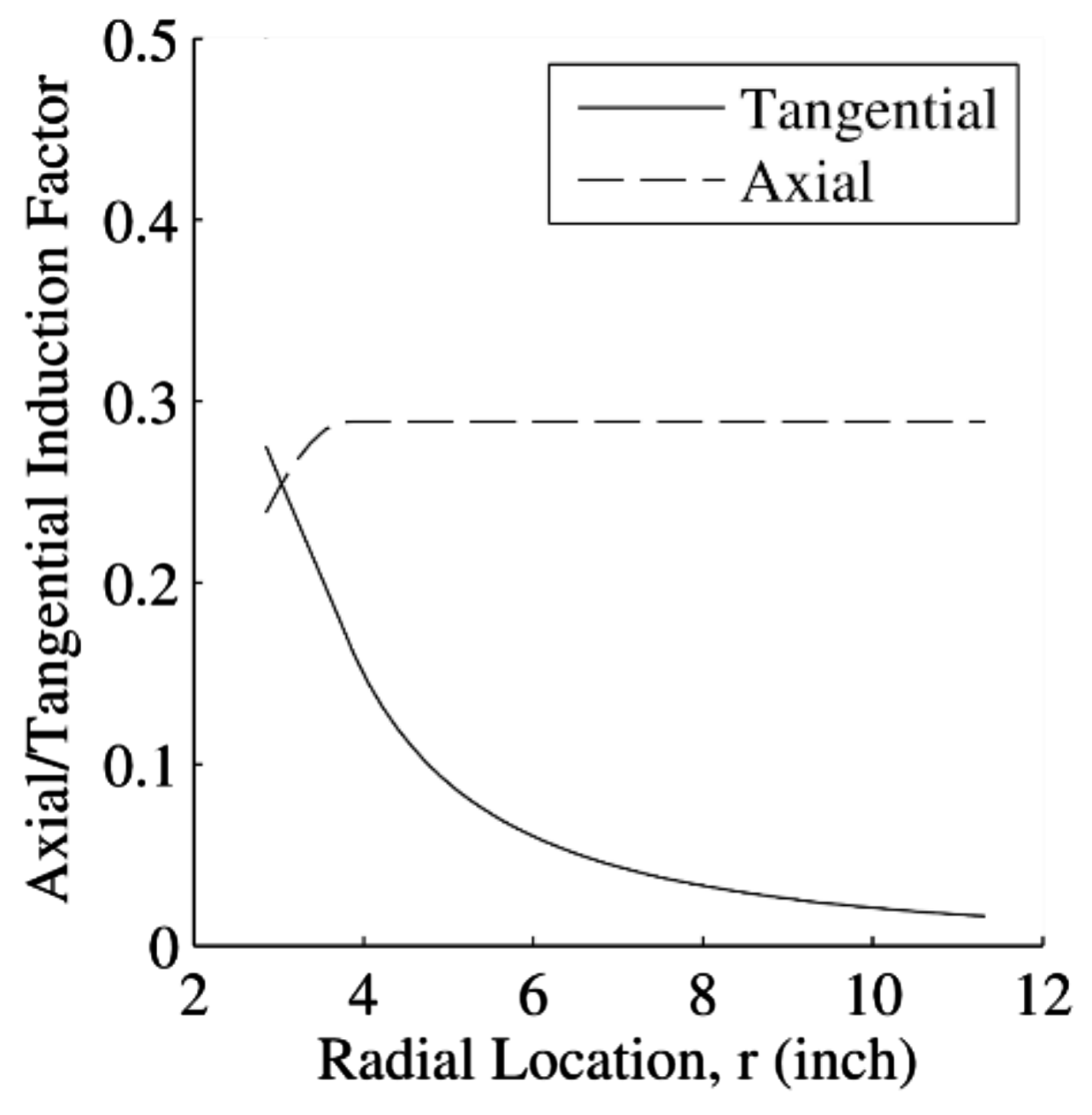




\section{Invoking Modification Option 2 to Step 1 reduces the very large increases in chord/pitch near the root}
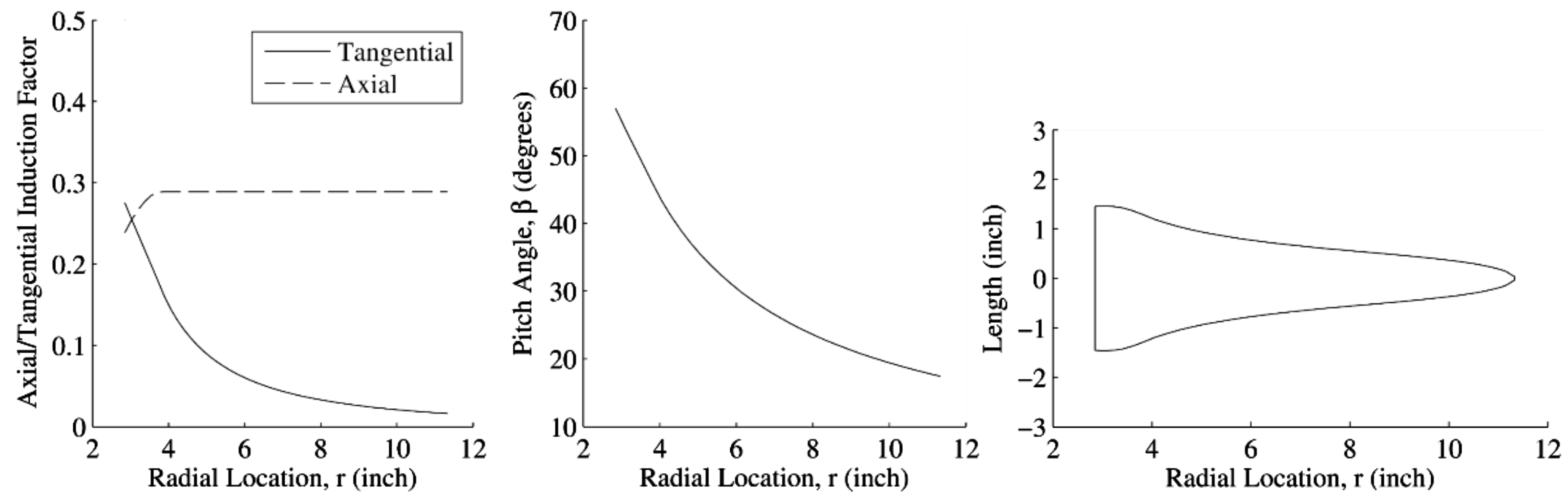

- With da'/d(r/R)=1.25 


\section{The method tends to produce designs with a velocity peak near the blade root}
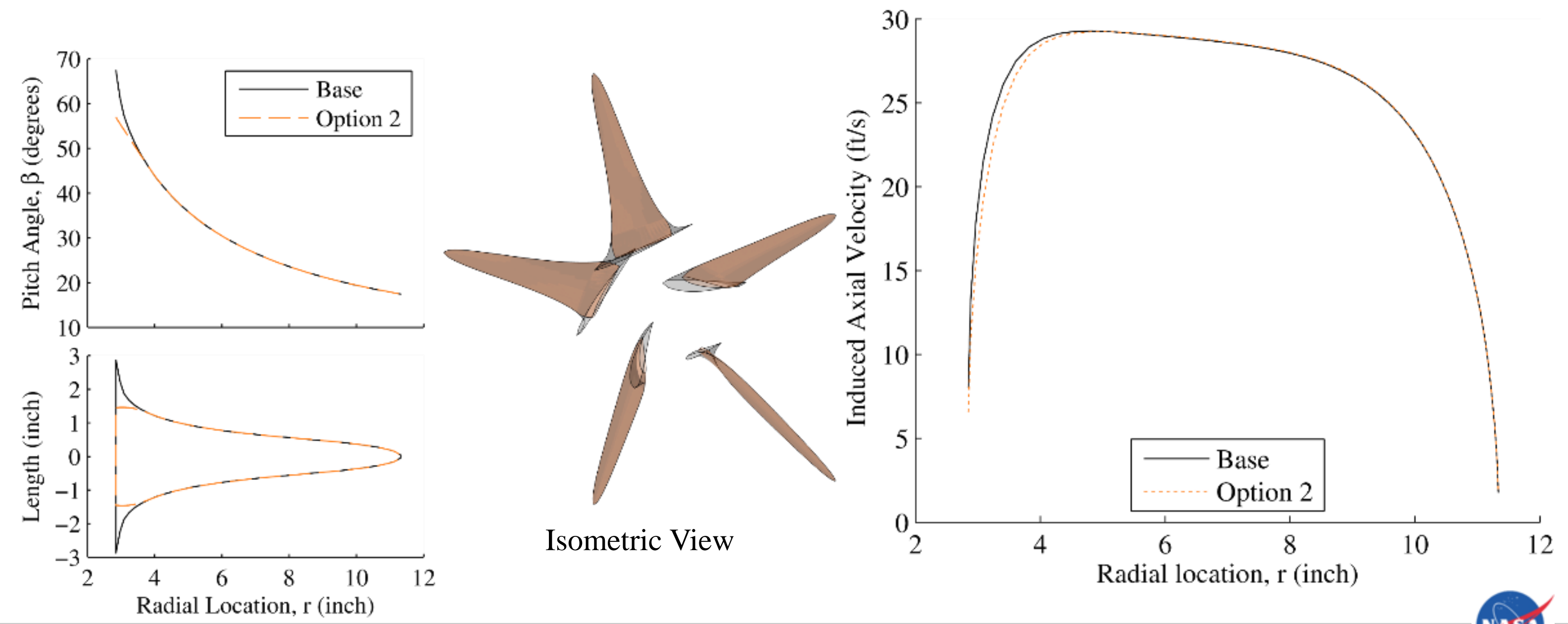


\section{Step 1, Modification Option 1: applying modified Prandtl tip loss factor to a provides desired blade loading at tip}

- Modify tip loss factor with larger radius

- Found $\mathrm{R}^{\prime}=1.035 \mathrm{R}$ provides desired results

$$
F=\frac{2}{\pi} \cos ^{-1}\left[e^{\frac{-B\left(R^{\prime}-r\right)}{2 r \sin (\varphi)}}\right] \quad a_{\text {mod }}=\frac{a}{F}
$$
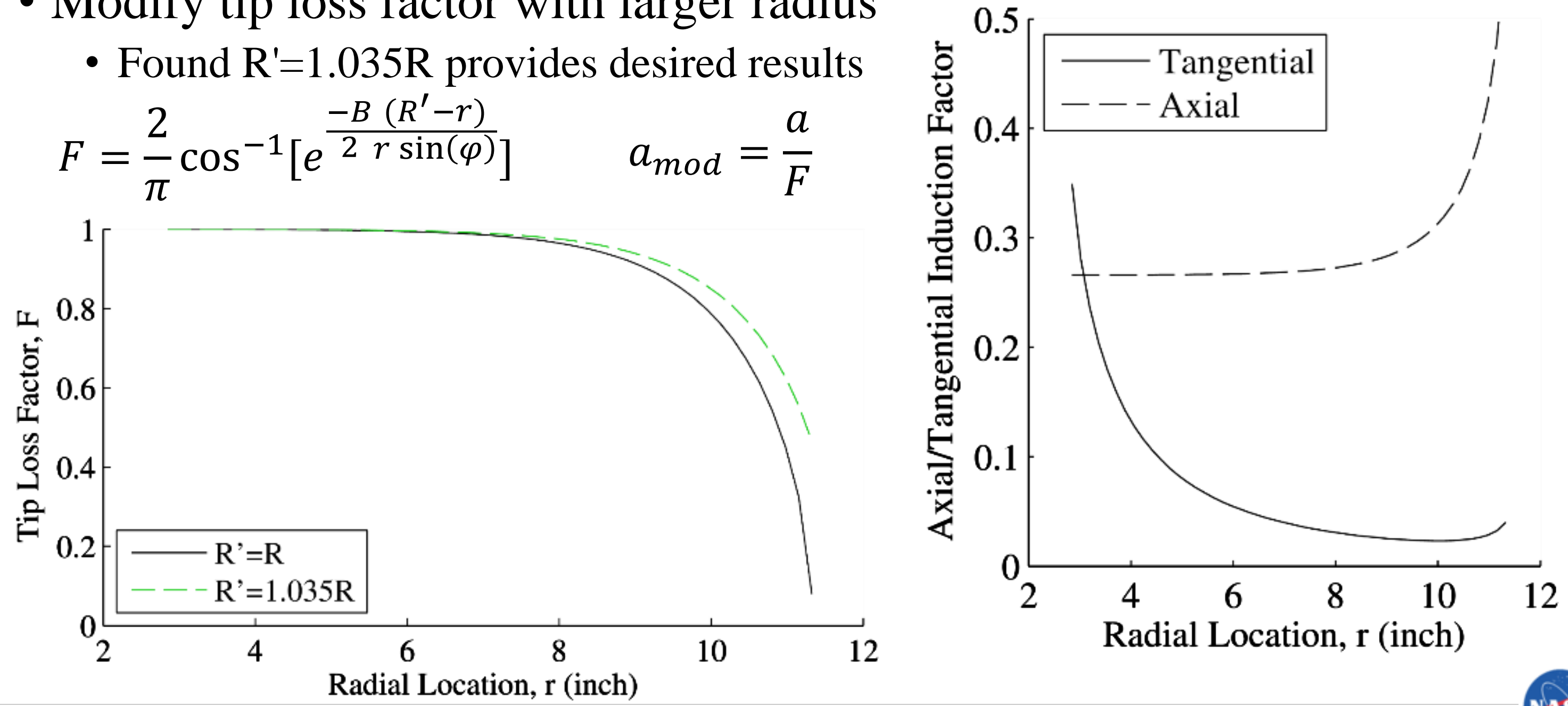


\section{Invoking Modification Option 1 to Step 1 increases the chord/pitch near tip and decreases chord/pitch near root}
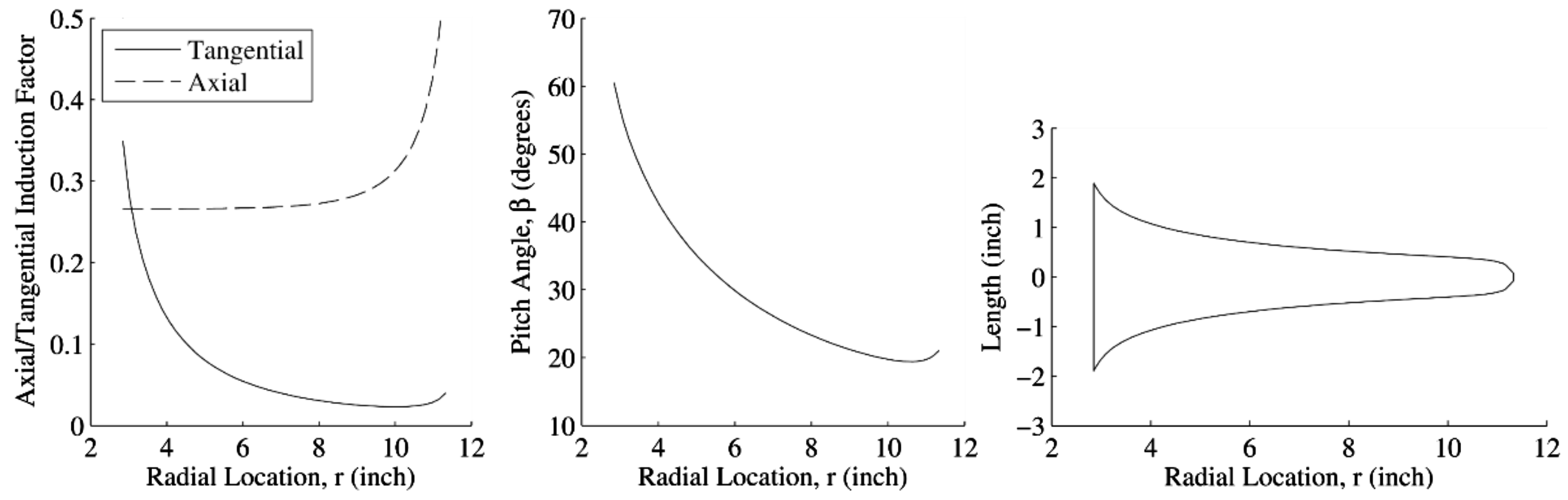

- With $\mathrm{R}^{\prime}=1.035$ 


\section{Invoking Modification Option 1 to Step 1 provides the desired near-uniform induced axial velocity distribution}

- Increased chord and pitch near tip

- Reduced chord and pitch near root

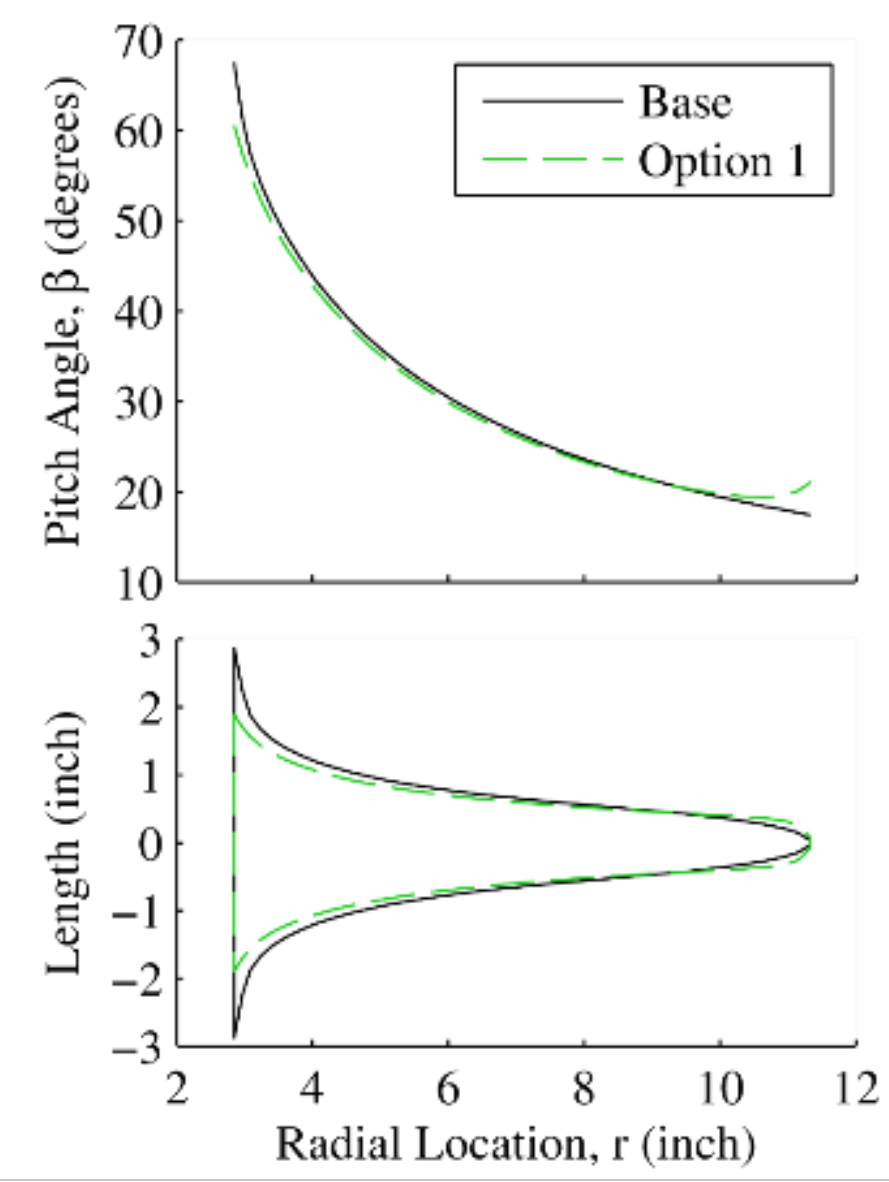

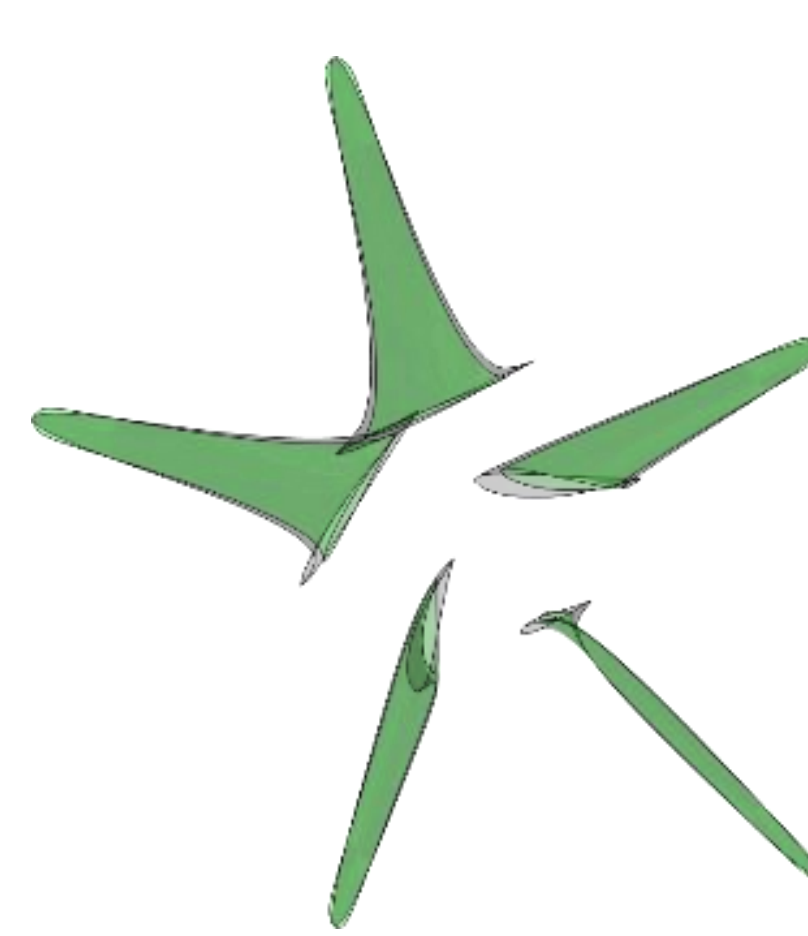

Isometric View

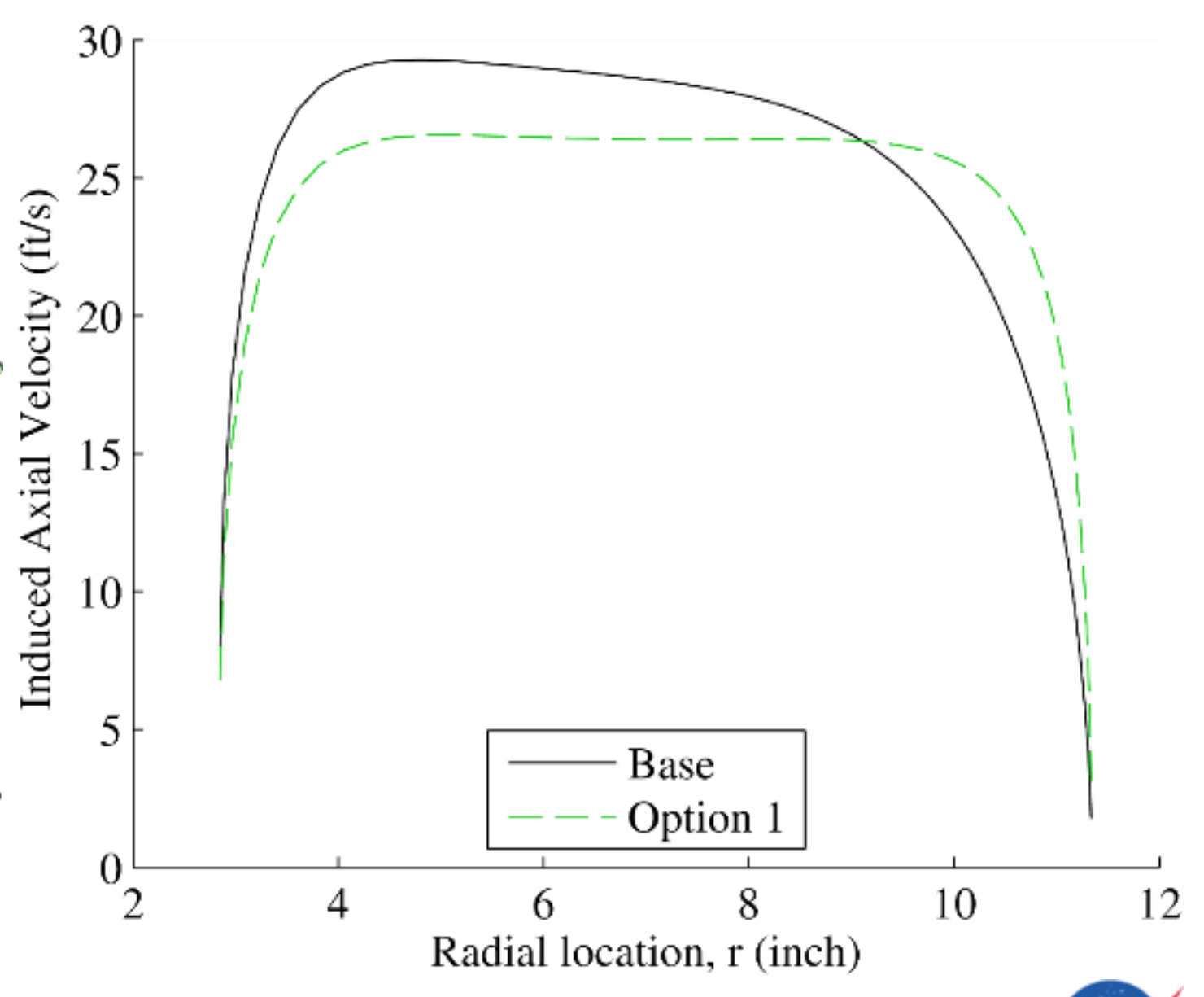




\section{Modification Options $1 \& 2$ when invoked simultaneously produce near-uniform velocities \& reasonable blade shapes}

- Slight decrease in induced axial velocity near root

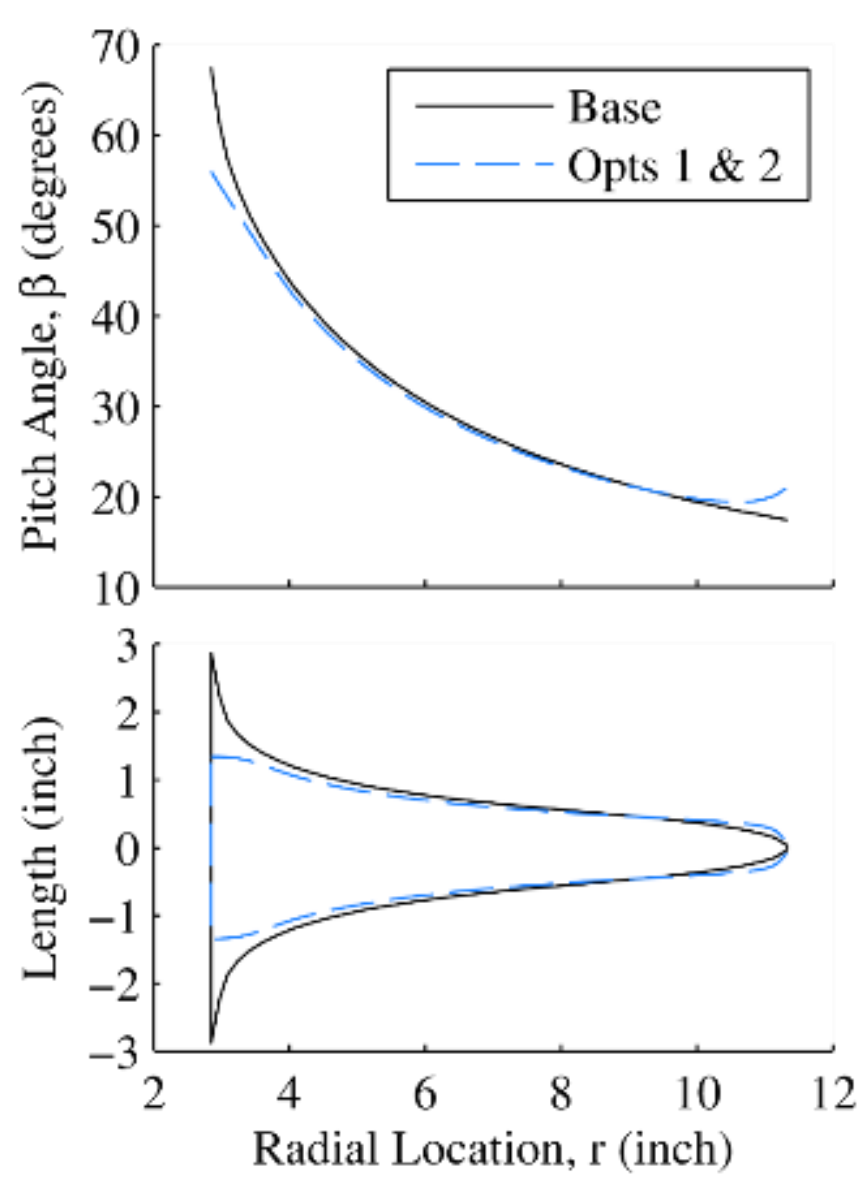

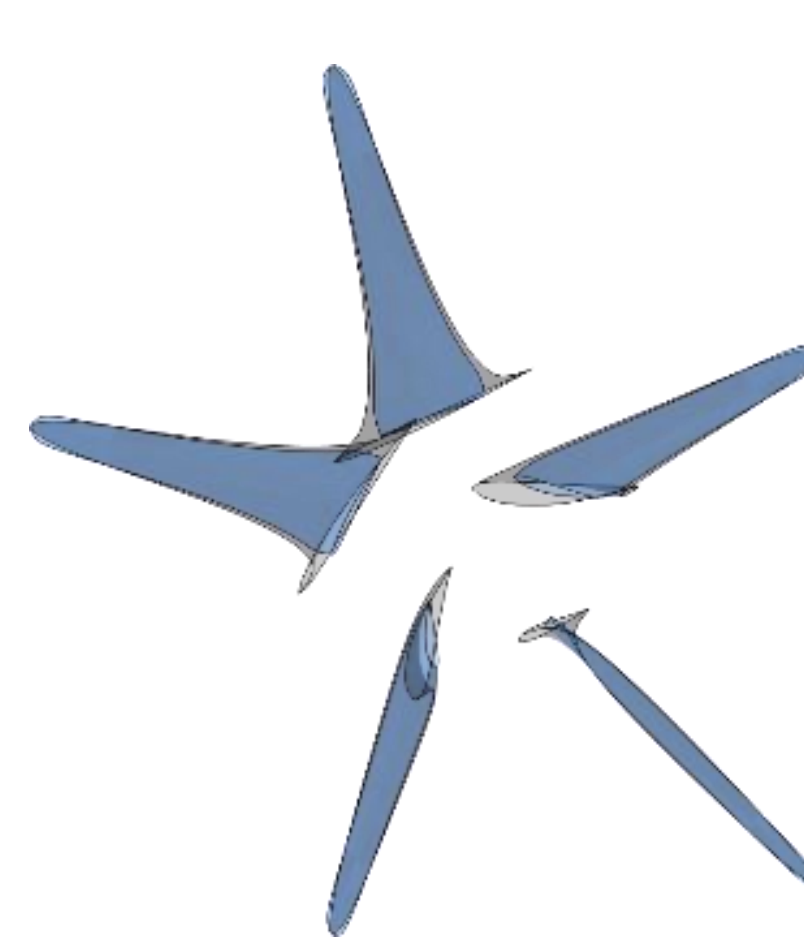

Isometric View

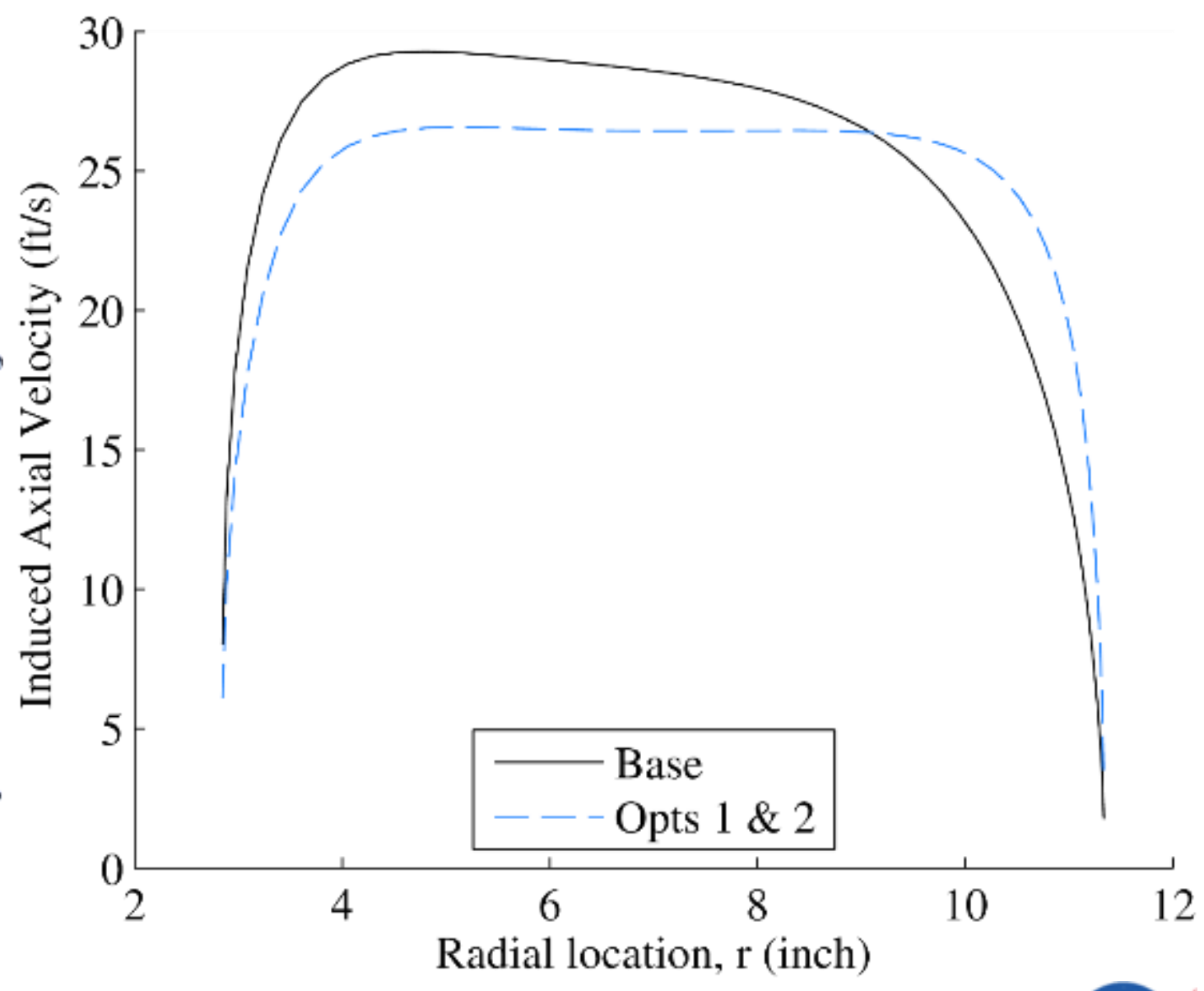




\section{Design method produces props with much more uniform velocity distributions than conventional props}
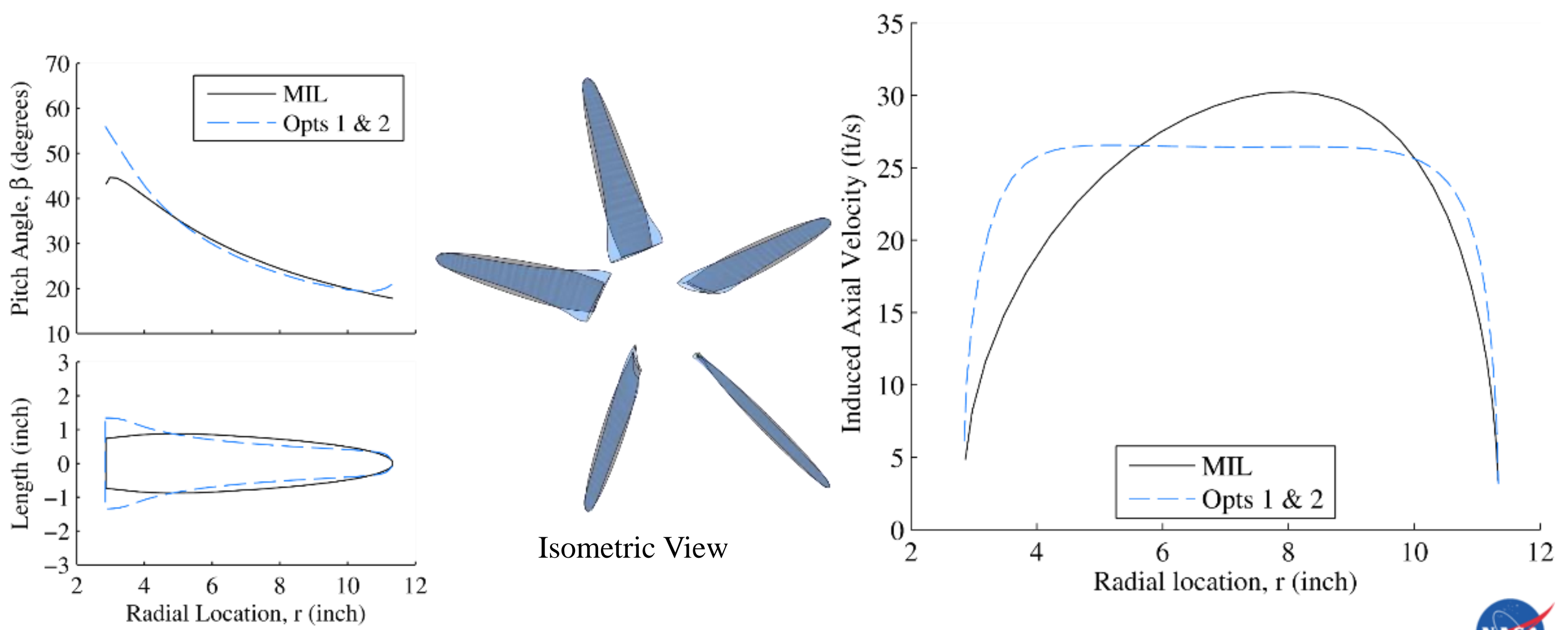


\section{Each new prop provides the same average induced axial velocity at $\sim 15 \%$ lower power than the MIL prop}

\begin{tabular}{l|cc|cc|cc}
\hline \hline & \multicolumn{2}{|c|}{$\begin{array}{c}\text { Power } \\
\text { \% }\end{array}$} & \multicolumn{2}{c|}{ Torque } & \multicolumn{2}{c}{ Thrust } \\
& kW & Difference & N-m & \% Difference & N & Difference \\
\hline MIL & 7.21 & -- & 15.1 & -- & 170 & -- \\
Base & 6.13 & $-15.0 \%$ & 12.9 & $-14.6 \%$ & 149 & $-12.4 \%$ \\
Option 1 & 6.17 & $-14.4 \%$ & 12.9 & $-14.6 \%$ & 151 & $-11.2 \%$ \\
Option 2 & 6.10 & $-15.4 \%$ & 12.8 & $-15.2 \%$ & 149 & $-12.4 \%$ \\
Opts 1 \& 2 & 6.16 & $-14.6 \%$ & 12.9 & $-14.6 \%$ & 151 & $-11.2 \%$ \\
\hline \hline
\end{tabular}
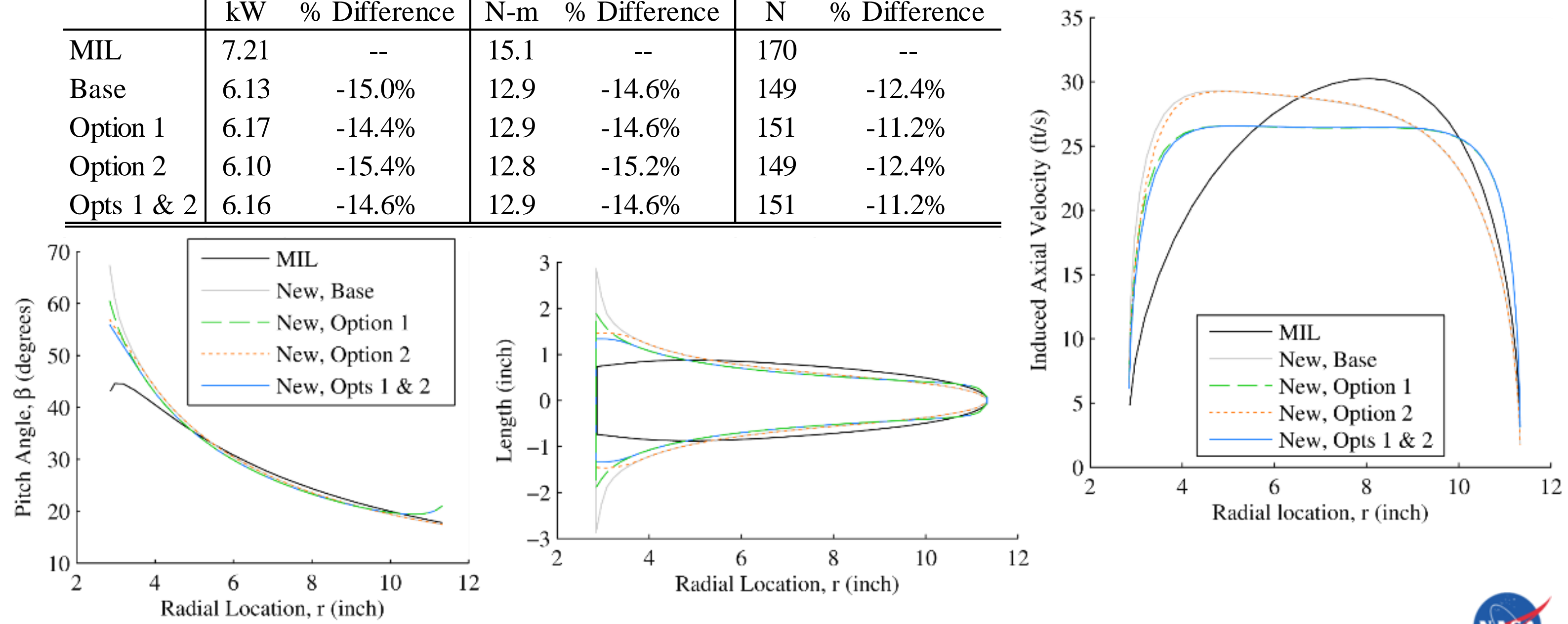


\section{Conclusions \& Future Work}




\section{The new prop designs are predicted to augment more lift than traditional props for a given power}

- Recall hypothesis: propellers with near-uniform axial velocity profiles will make the most effective high-lift propellers

- Conclusions

- Design method produces the desired near-uniform induced axial velocity profile

- Design method produces high-lift props with $\sim 15 \%$ lower powers and $\sim 11 \%$ lower thrusts than traditional methods to produce the same average induced axial velocity

- Future work

- Wind tunnel testing and/or unsteady CFD are required to validate performance predictions

- Consider removing assumption that the rotational velocity added to the slipstream is small

- Study impacts of large pitch angles near root on blade folding

- Study impacts of varying airfoils along blade

- Aeroelastic analysis 


\section{Questions?}

This work was funded under the Convergent Aeronautics Solutions (CAS) and Transformational Tools and Technologies (TTT) Projects of NASA's Transformative Aeronautics Concepts Program. 
(13.)

\section{Backup}




\section{The average induced axial velocity is found via an area-weighted average}

- For incompressible flow, areaweighted average is same as mass flow-weighted average

$\left(V_{a}\right)_{\text {avg }}=\frac{\sum_{i=1}^{n}\left\{\pi\left(r_{i+1}^{2}-r_{i}^{2}\right) 0.5\left[V_{a}\left(r_{i+1}\right)+V_{a}\left(r_{i+1}\right)\right]\right\}}{\pi\left(R^{2}-r_{h u b}^{2}\right)}$

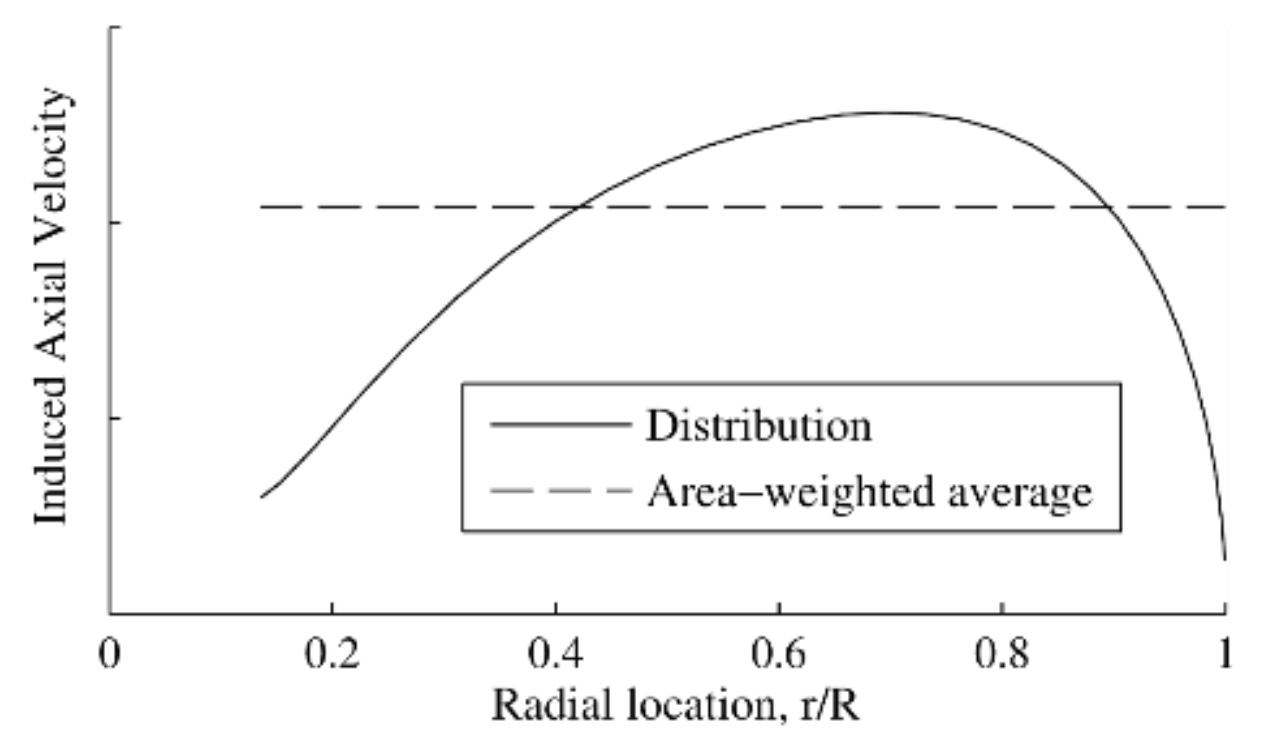




\section{Comparison of MIL prop and Base new prop}

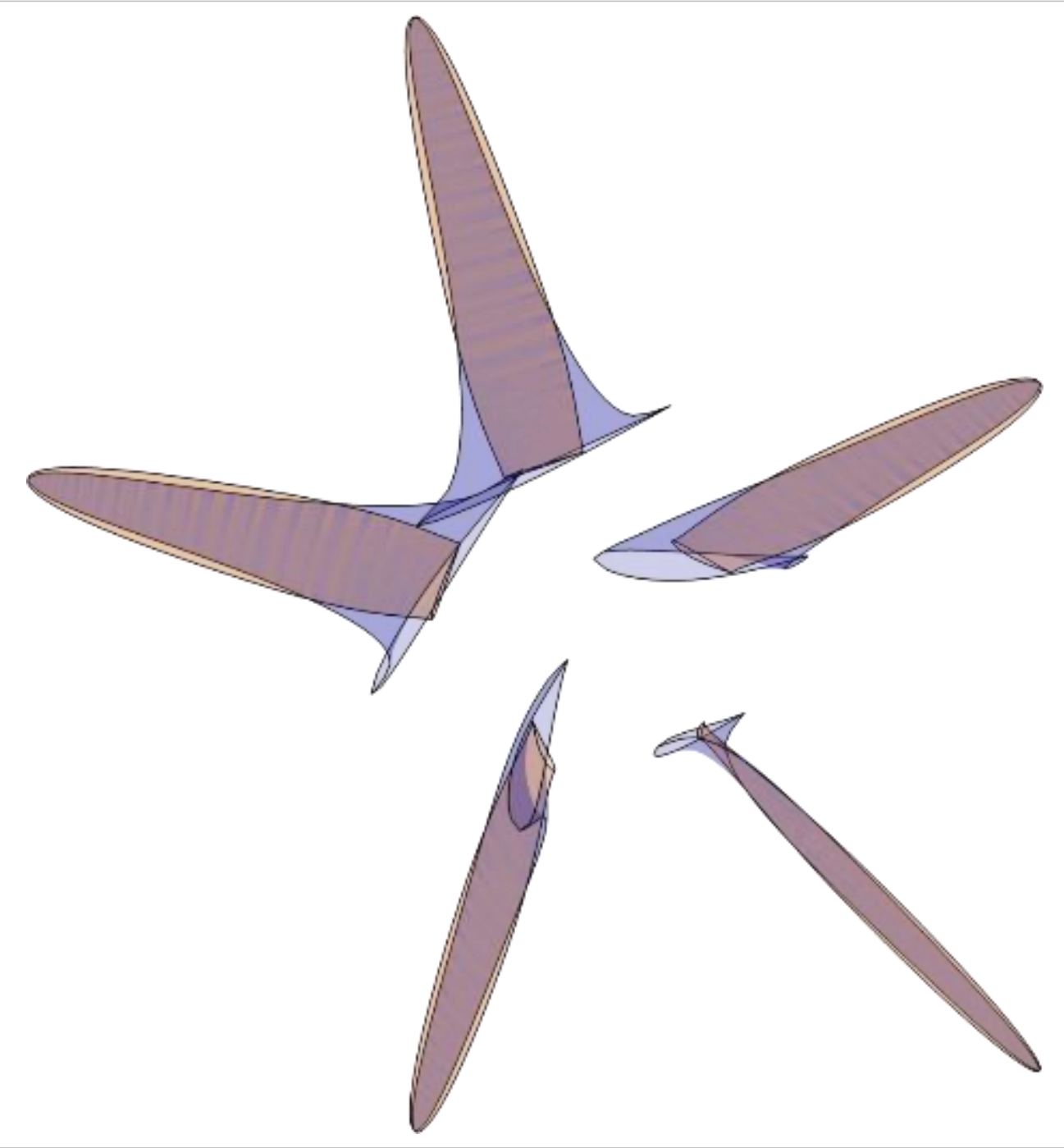




\section{Comparison of MIL prop and new prop with Optional Step 1}

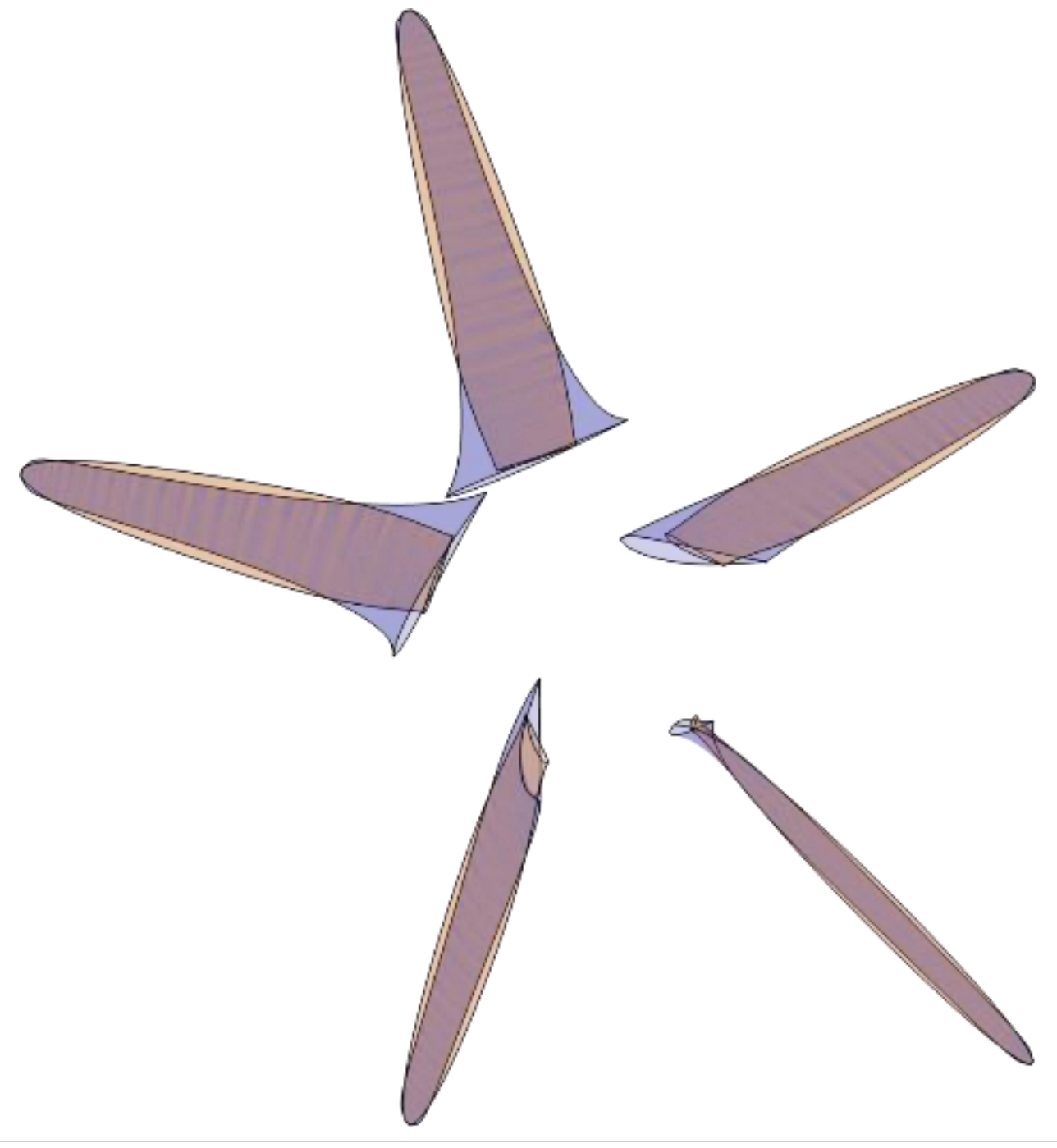




\section{Comparison of MIL prop and new prop with Optional Step 2}

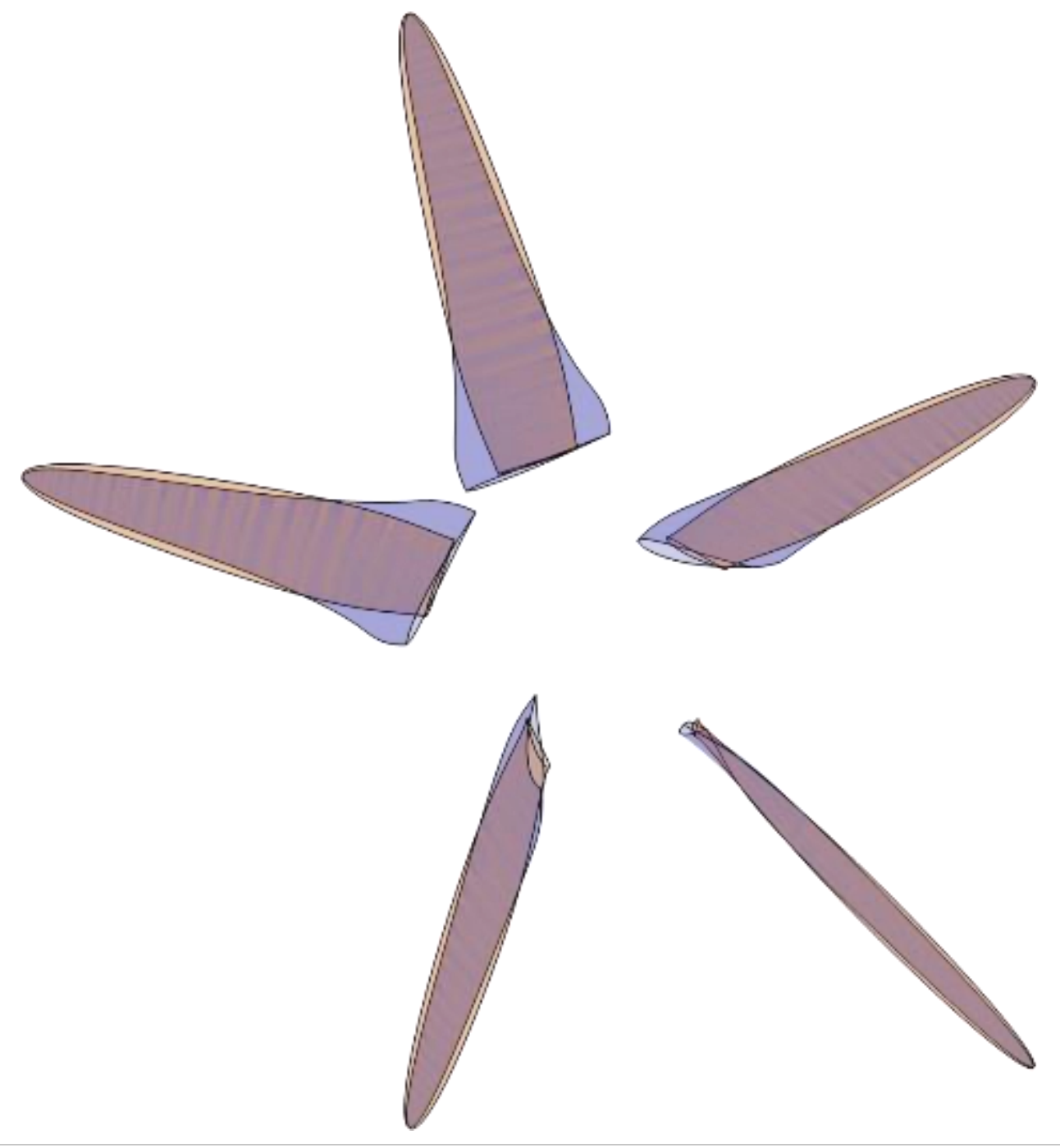




\section{Comparison of MIL prop and new prop with Optional Steps 1 \& 2}
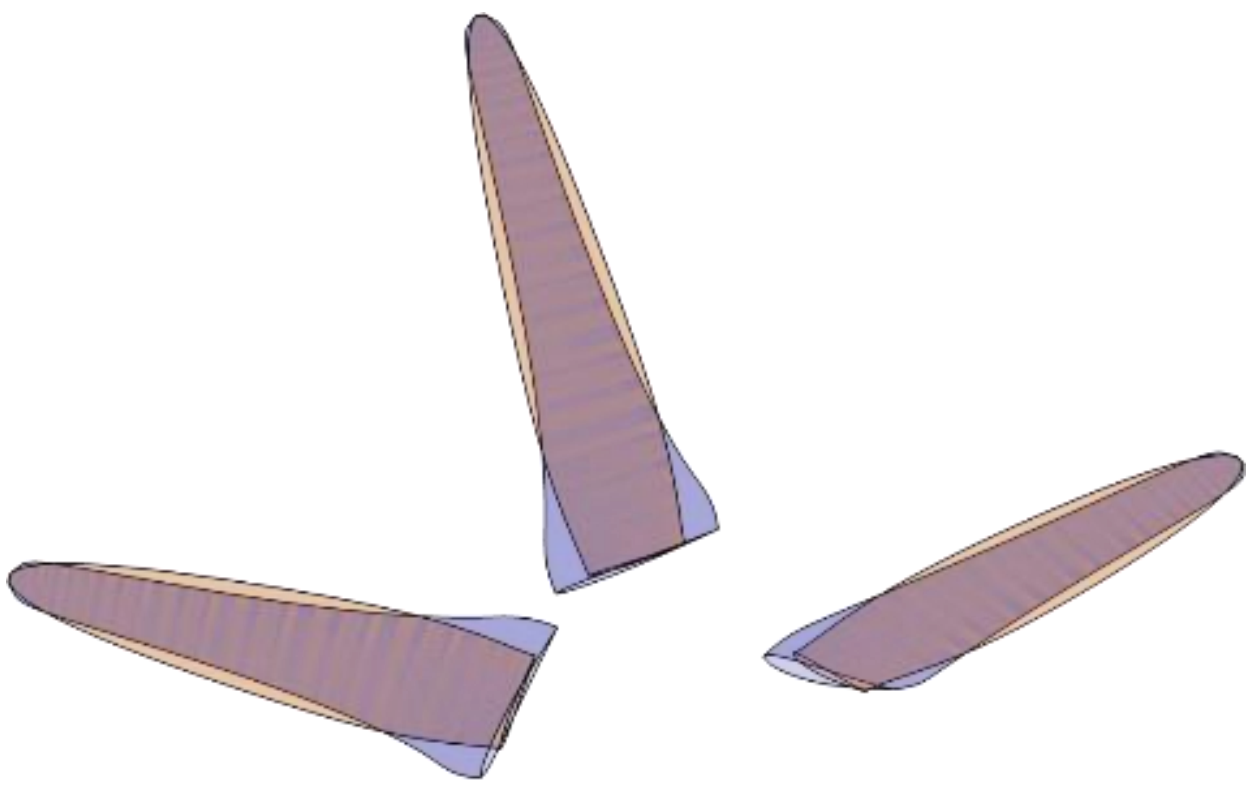


\section{The design method is based on BEMT and seeks to maintain a near-uniform axial velocity distribution}

- Method is built on blade element momentum theory (BEMT)

- Analyze prop as sum of many "blade elements" as 2-D airfoils

- Local velocity split into axial and tangential components, which are defined by the freestream, prop rotation, and prop-induced velocities

- Induced velocities presented as axial and tangential induction factors ( $a$ and $a^{\prime}$ )

- We assume that the angular velocity added to the slipstream is small compared to the angular velocity of the propeller

- Method has four main steps:

1. Set axial induction factor distribution

2. Determine blade twist angle distribution

3. Determine blade chord length distribution

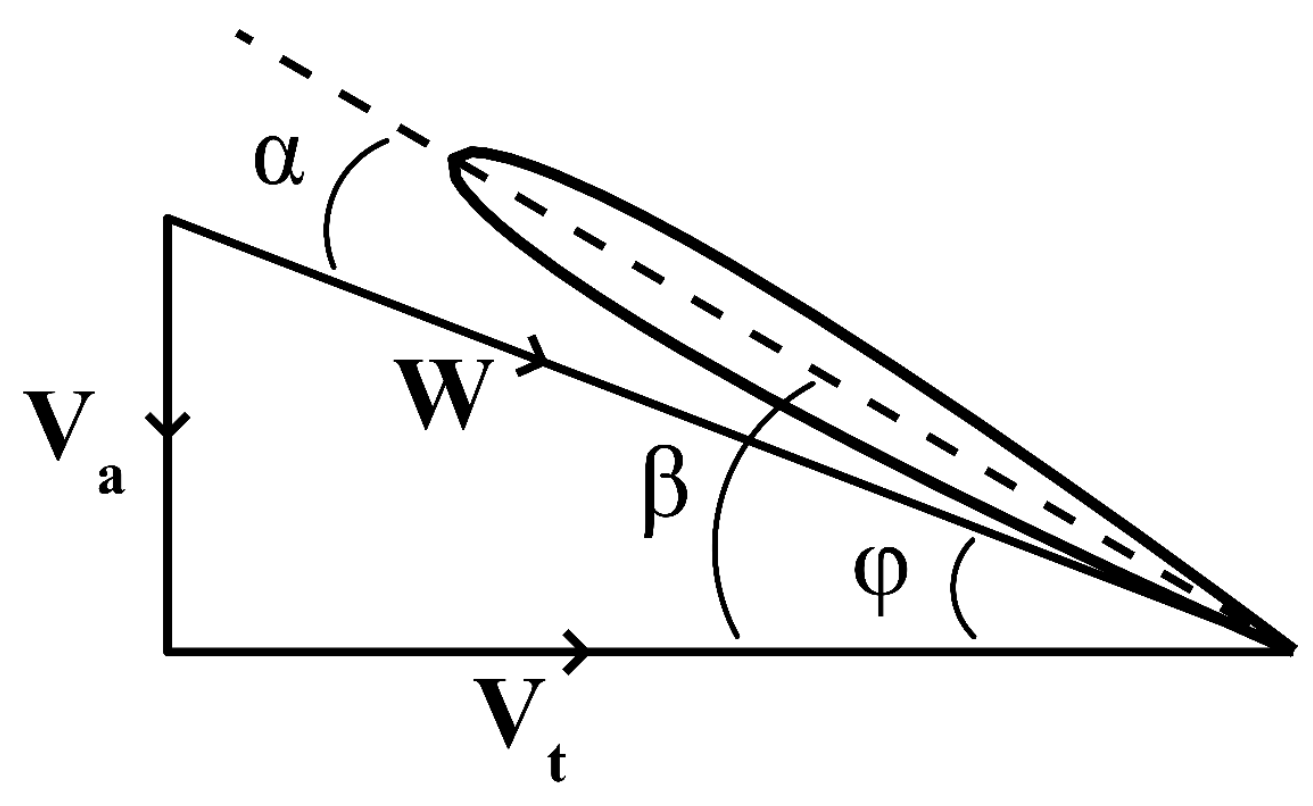

4. Verify performance and iterate (if required)

$\boldsymbol{V}_{\boldsymbol{a}}=V_{\infty}(1+a)$

$\boldsymbol{V}_{\boldsymbol{t}}=\Omega r\left(1-a^{\prime}\right)$ 


\section{Changing the maximum value of the slope can have large impacts on the resulting geometry}
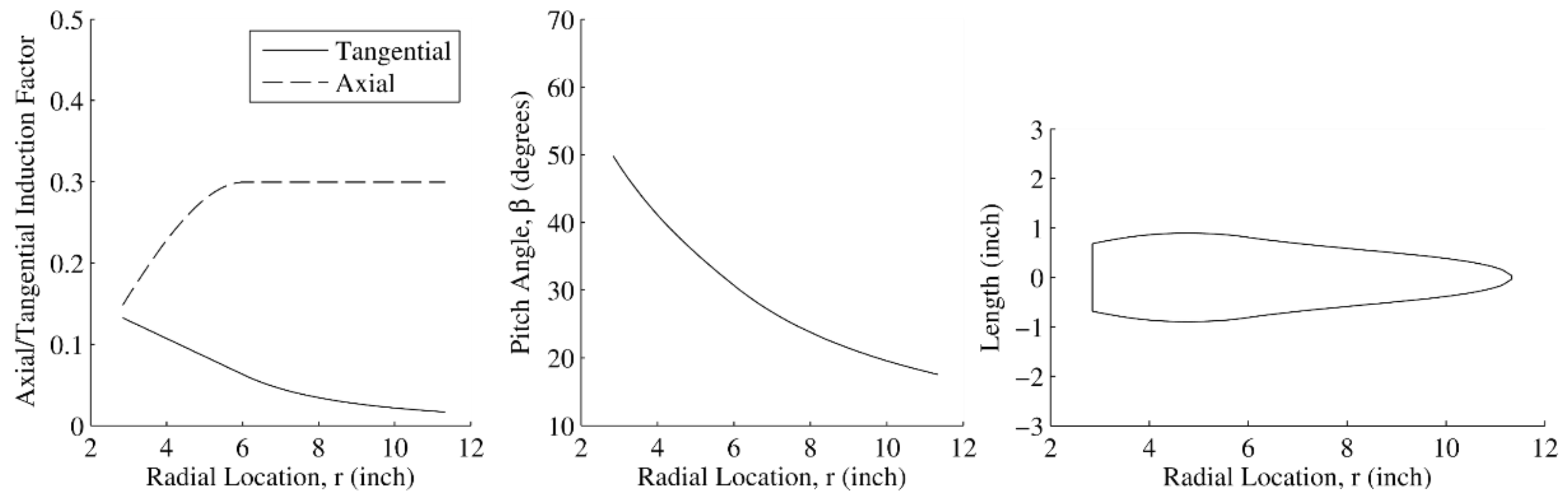

- With da'/d(r/R)=0.25 


\section{Step 2: Determine blade pitch angle distribution}

- Calculate inflow angle, $\varphi$, with axial and tangential induction factors from Step 1

- For desired airfoil(s), specify desired angle of attack / section lift coefficient distribution

- If only concerned with point performance, select $\alpha$ for max L/D

- Other considerations such as off-design point operation may lead to different $\alpha$ distribution

- Blade twist found from inflow angle and

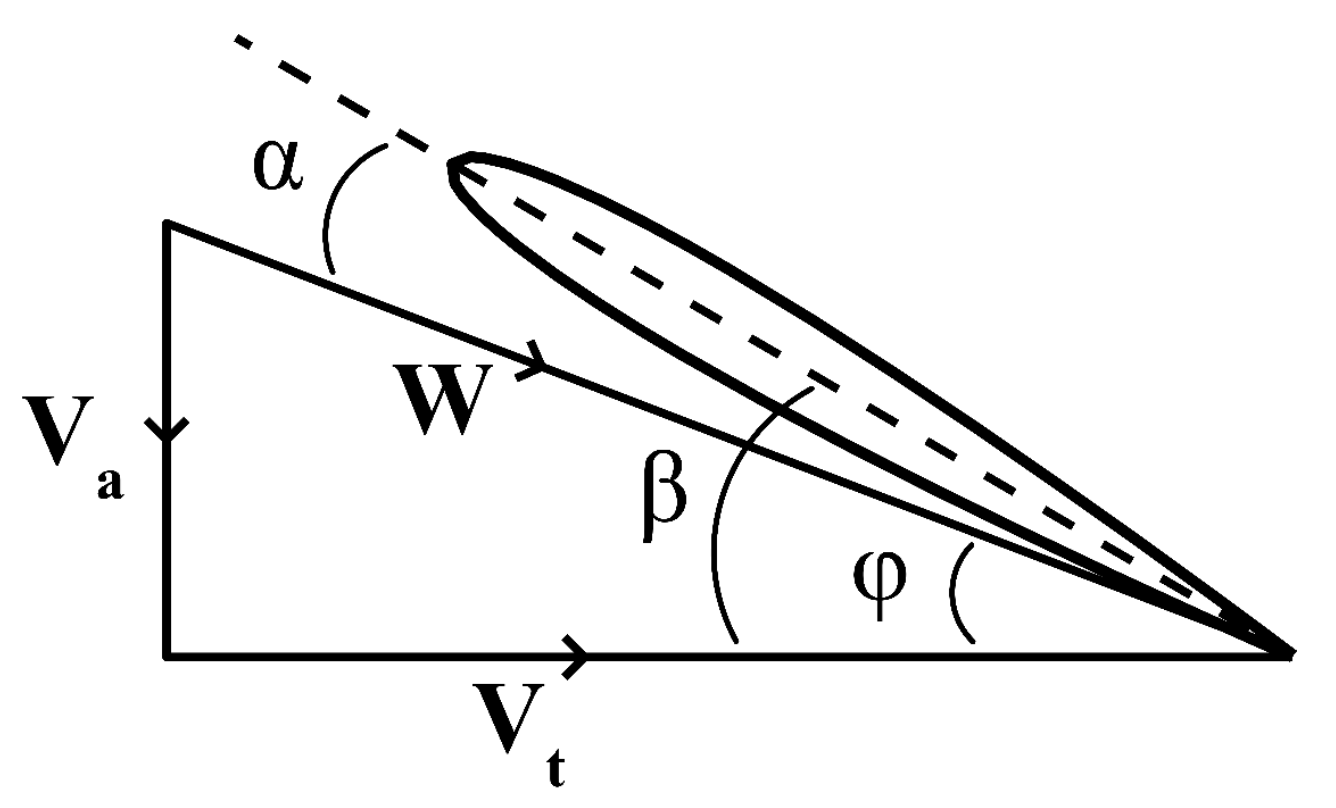
angle of attack distributions

$$
\varphi=\tan ^{-1}\left(\frac{V_{\infty}(1+a)}{\Omega r\left(1-a^{\prime}\right)}\right)
$$

$$
\beta=\varphi+\alpha
$$




\section{Step 3: Determine blade chord length distribution}

- The thrust from an annulus of the prop disk can be expressed in two equations

$$
d T=4 \pi r \rho V_{\infty}^{2}(1+a) a F d r
$$

- One from momentum theory and the other blade element theory

- Only unknown is the chord length

$$
d T=\frac{B}{2} \rho W^{2}\left[c_{l} \cos (\varphi)-c_{d} \sin (\varphi)\right] c d r
$$

- Equate two expressions for thrust and solve for the chord length

- Assumes the airfoil aerodynamic characteristics are known

- Number of blades must be specified

$$
\text { where } \quad F=\frac{2}{\pi} \cos ^{-1}\left[e^{-\frac{B(R-r)}{2 r \sin (\varphi)}}\right]
$$

$$
c=\frac{8 \pi r V_{\infty}^{2}(1+a) F}{B W^{2}\left[c_{l} \cos (\varphi)-c_{d} \sin (\varphi)\right]}
$$




\section{Step 1, Modification Option 1: increase induced axial velocity near tip}

- Desire to increase axial velocity near tip

- Use Prandtl tip loss factor to account for tip losses

$$
F=\frac{2}{\pi} \cos ^{-1}\left[e^{\frac{-B\left(R^{\prime}-r\right)}{2 r \sin (\varphi)}}\right] \quad a_{\text {mod }}=\frac{a}{F}
$$
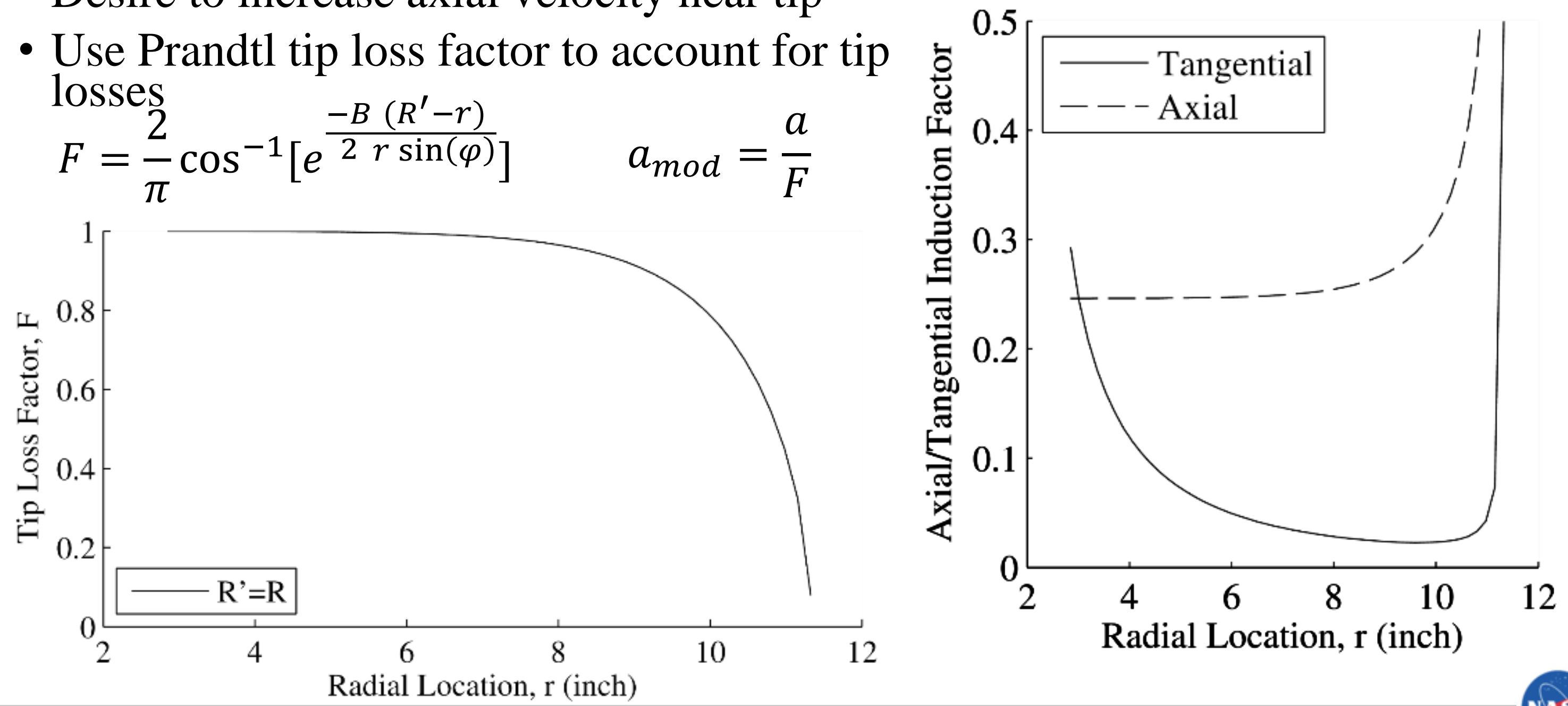